\title{
Infection Structure-Specific Reductive Iron Assimilation Is Required for Cell Wall Integrity and Full Virulence of the Maize Pathogen Colletotrichum graminicola
}

\author{
Emad Albarouki ${ }^{1}$ and Holger B. Deising ${ }^{1,2}$ \\ ${ }^{1}$ Interdisziplinäres Zentrum für Nutzpflanzenforschung and ${ }^{2}$ Institut für Agrar- und Ernährungswissenschaften, \\ Phytopathologie und Pflanzenschutz, Martin-Luther-Universität Halle-Wittenberg, Betty-Heimann-Str. 3, D-06120 Halle \\ (Saale), Germany
}

Submitted 5 January 2013. Accepted 20 February 2013.

Ferroxidases are essential components of the high-affinity reductive iron assimilation pathway in fungi. Two ferroxidase genes, FET3-1 and FET3-2, have been identified in the genome of the maize anthracnose fungus Colletotrichum graminicola. Complementation of growth defects of the ferroxidase-deficient Saccharomyces cerevisiae strain $\Delta$ fet3fet4 showed that both Fet3-1 and Fet3-2 of $C$. graminicola represent functional ferroxidases. Expression of enhanced green fluorescent protein fusions in yeast and C. graminicola indicated that both ferroxidase proteins localize to the plasma membrane. Transcript abundance of FET3-1 increased dramatically under iron-limiting conditions but those of FET3-2 were hardly detectable. $\Delta f e t 3-1$ and $\Delta f e t 3-2$ single as well as $\Delta f e t 3-1 / 2$ double-deletion strains were generated. Under iron-sufficient or deficient conditions, vegetative growth rates of these strains did not significantly differ from that of the wild type but $\Delta f e t 3-1$ and $\Delta f e t 3-1 / 2$ strains showed increased sensitivity to reactive oxygen species. Furthermore, under iron-limiting conditions, appressoria of $\Delta f e t 3-1$ and $\Delta f e t 3-1 / 2$ strains showed significantly reduced transcript abundance of a class $V$ chitin synthase and exhibited severe cell wall defects. Infection assays on intact and wounded maize leaves, quantitative data of infection structure differentiation, and infection stage-specific expression of FET3-1 showed that reductive iron assimilation is required for appressorial penetration, biotrophic development, and full virulence.

Iron is the most prominent redox element in living cells and a co-factor of enzymes catalyzing rapid redox reactions such as iron-sulfur proteins and cytochromes. Thus, iron is considered an indispensable element for almost all organisms (Haas 2003; Kosman 2003). Paradoxically, although an essential element, iron can be harmful to cells, due to its participation in production of hydroxyl radicals by the Fenton/Haber Weiss reaction (Halliwell and Gutteridge 1984, 1992). Therefore, iron homeostasis must be tightly controlled by iron concentration-

Corresponding author: H. B. Deising; Telephone: +49-345-5522660; Email: holger.deising@landw.uni-halle.de

* The $\boldsymbol{e}$-Xtra logo stands for "electronic extra" and indicates that four supplementary figures and one supplementary table are published online.

(C) 2013 The American Phytopathological Society dependent regulation of iron uptake, transport and, storage within cells and organisms.

Although iron is the fourth most abundant element in Earth's crust, its bioavailability is extremely low. At neutral $\mathrm{pH}$, the solubility product of $\mathrm{Fe}^{3+}$, the main oxidation state in an aerobic environment, is less than $10^{-18} \mathrm{M}$ (Neilands et al. 1987). Compared with iron-rich terrestrial environments, the availability of iron may be significantly lower for pathogenic fungi growing in plant or animal hosts (Expert 1999; Weinberg 1978, 2009), due to tight iron sequestration by ferritin, transferrins, or several other iron-binding proteins (Arosio and Levi 2002; Ratledge and Dover 2000). Because iron-dependent generation of reactive oxygen species (ROS) contributes to the first line of plant defense, and because iron is required for detoxification of ROS by the pathogen (Hidalgo et al. 1997; Welinder 1992), competitive iron uptake by the invading hypha serves different functions (i.e., weakening of plant defense, protection of infection hyphae from ROS, and provision with an essential redox element required for fungal development) (Haas et al. 2008). Thus, the ability to efficiently take up iron can be regarded as a key factor for pathogenicity.

Four different iron uptake systems (i.e., reductive iron assimilation [RIA], siderophore-mediated $\mathrm{Fe}^{3+}$ uptake, heme uptake, and direct $\mathrm{Fe}^{2+}$ uptake) have been identified in fungi, with RIA and siderophore-mediated $\mathrm{Fe}^{3+}$ uptake representing high-affinity iron acquisition systems (Haas et al. 2008; Philpott 2006). Iron uptake via RIA is a two-step process. First, plasma membranelocalized iron reductases catalyze extracellular reduction of insoluble or chelator-complexed ferric $\left(\mathrm{Fe}^{3+}\right)$ to soluble ferrous $\left(\mathrm{Fe}^{2+}\right)$ iron. Subsequently, $\mathrm{Fe}^{2+}$ is bound by a bipartite high-affinity iron transport complex, consisting of a multicopper ferroxidase (Fet3), and an iron permease (Ftr1), transferred across the plasma membrane, and delivered into the cytoplasm as $\mathrm{Fe}^{3+}$ (Eide 1997; Haas et al. 2008; Shi et al. 2003). Thus, high-affinity translocation requires Fet3-mediated oxidation of iron. The advantage gained by this mechanism of iron uptake is unknown but one may speculate that it confers specificity for iron, because other divalent ions are not prone to changes in their redox status and, therefore, are excluded from the RIA-mediated uptake system (Eide 1997; Haas et al. 2008; Kosman 2003).

In the biotrophic maize smut fungus Ustilago maydis, two components of the high-affinity RIA system (i.e., the high-affinity iron permease Fer2 and the iron multicopper oxidase Fer1) were studied. Both $\Delta f e r 2$ and $\Delta f e r l$ deletion mutants were severely affected in virulence, demonstrating the importance of this iron-uptake pathway for biotrophic development of $U$. maydis on maize (Eichhorn et al. 2006). Likewise, mutants of 
the dimorphic human pathogen Candida albicans lacking the iron permease Ftr1 exhibited severe growth defects in iron-deficient medium and were unable to establish systemic infection in mice, indicating that iron uptake via RIA also is essential for full virulence in this pathogen (Ramanan and Wang 2000). In Cryptococcus neoformans, which is also a dimorphic pathogen of mammals, one of the two ferroxidases, Cfo1, is required for utilization of transferrin, an important iron source during infection, and virulence of a $c f o l$ mutant was clearly attenuated in mice (Jung et al. 2009). By contrast, in the filamentous ascomycete Gibberella zeae (anamorph: Fusarium graminearum), a necrotroph causing head blight in wheat and barley and ear rot

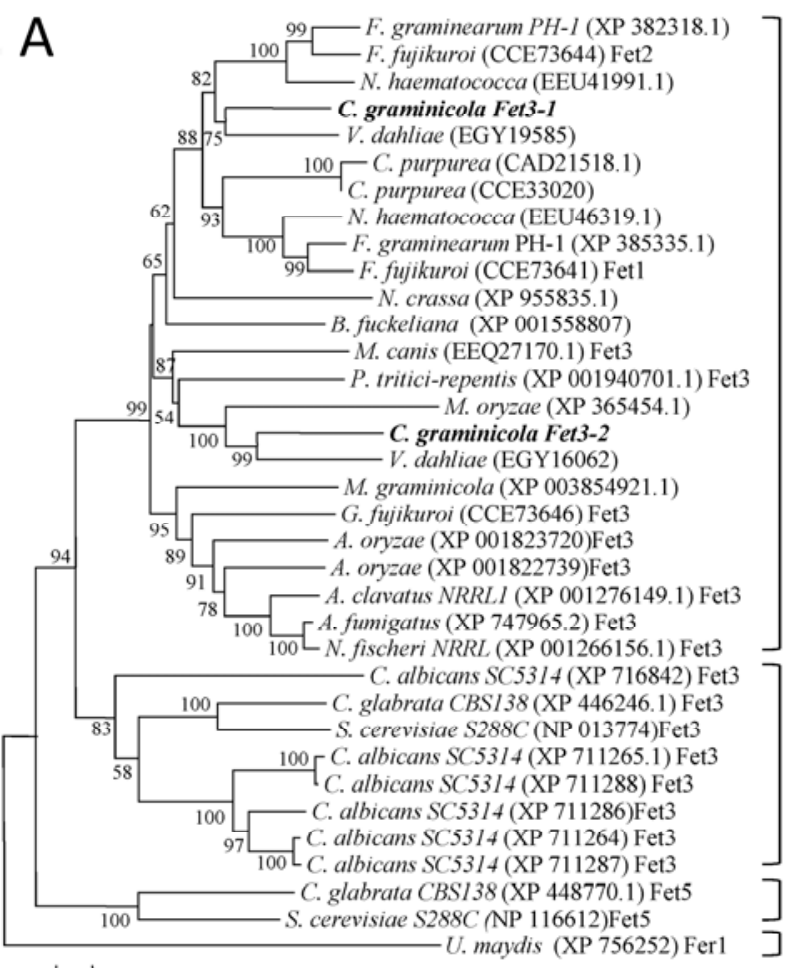

B

Colletotrichum graminicola $\mathrm{Chr} .2$

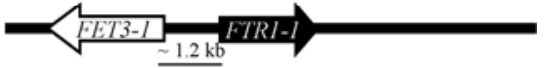

Colletotrichum graminicola Chr. 5

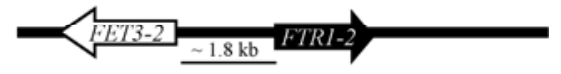

Fusarium graminearum Chr. 1

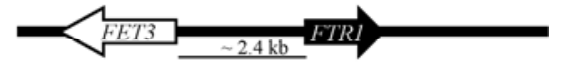

Fusarium graminearum Chr. 3

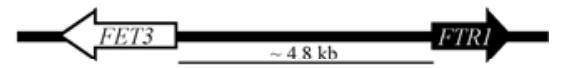

Nectria haematococca Chr. 4

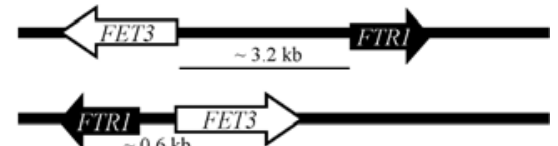

Nectria haematococca Chr. 10

Aspergillus oryzae

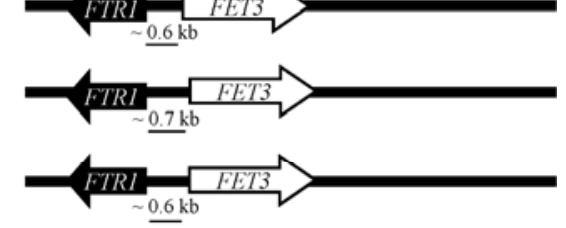

Aspergillus oryzae

$\stackrel{\longmapsto}{0.05}$

C

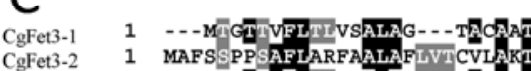

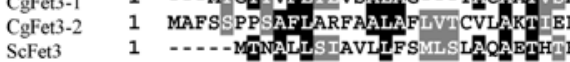

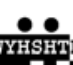

- BOX 1
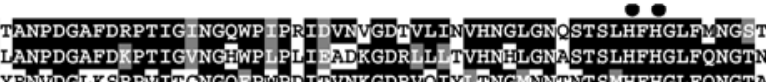

ADKGDR L TVHNHLG

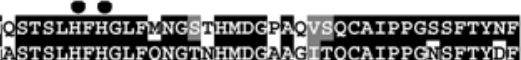

TAMDGAMGITQCAIPPGNSTYDI

BOX 2

$\operatorname{BOX} 3$

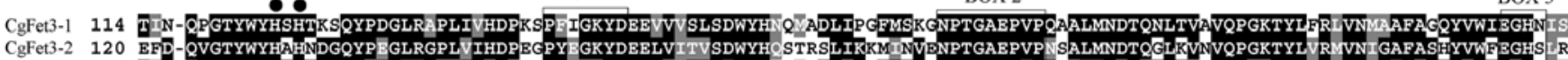

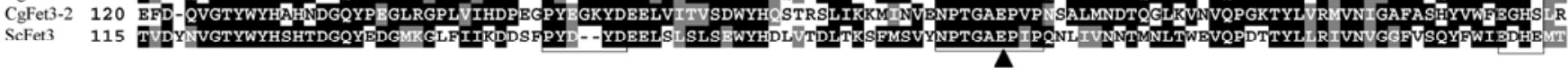

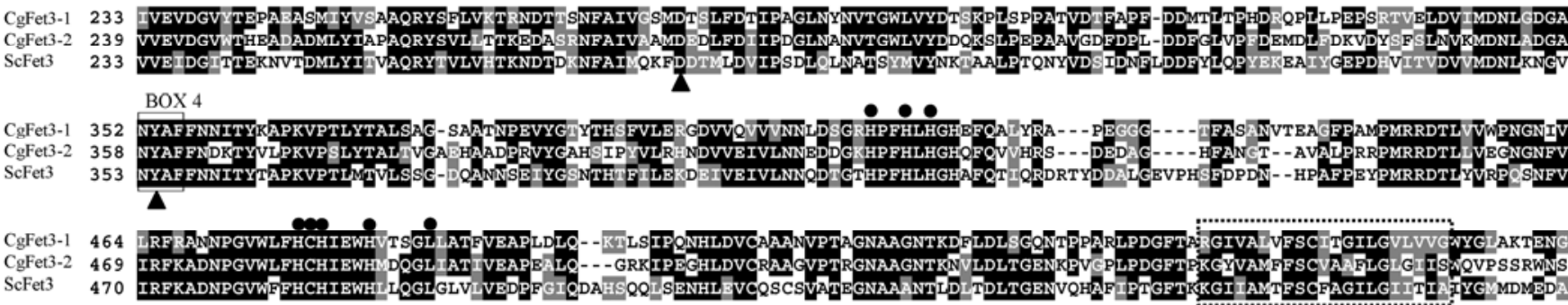

CgFet3-1 582 PSRVGYA-GSASVAQTG--DGQREETVMVGAAS- - -GGAGAGRT - - - 619

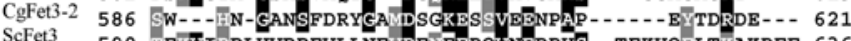

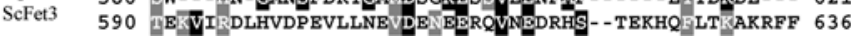

Fig. 1. Phylogeny and conserved regions of fungal ferroxidases, and chromosomal localization of FET3 and FTR1 genes. A, Phylogenetic tree of putative ferroxidases of different fungi. Ferroxidases of Colletotrichum graminicola show high similarity with those of other filamentous ascomycetes. Fusarium fujikuroi(CCE 73644, CCE 73641, CCE 73646), F. graminearum (XP 382318.1, XP 385335.1), Nectria haematococca (EEU 41991.1, EEU 46319.1), Verticillium dahliae (EGY 19585, EGY 16062), Claviceps purpurea (CAD 21518.1, CCE 33020), Neurospora crassa (XP 955835.1), Botryotinia fuckeliana (XP 001558807), Microsporum canis (EEQ 27170.1), Pyrenophora tritici-repentis (XP 001940701.1), Magnaporthe oryzae (XP 3708928.1), Mycosphaerella graminicola (XP 003854921.1), Aspergillus clavatus (XP 001276149.1), A. fumigatus (XP 747965.2), A. oryzae (XP 001823720, XP 001822739), and Neosartorya fischeri (XP 001266156.1); whereas the dimorphic fungi Candida albicans (XP 716842, XP 711265.1, XP 711288, XP 711286, (XP 711264, XP 711287) and C. glabrata (XP 446246.1, XP 448770.1) ferroxidases show high similarity to the yeast Saccharomyces cerevisiae ferroxidases (NP 013774, NP 116612). Ustilago maydis ferroxidase Fer1 (XP 756252) was used as out-group. B, Chromosomal localization of ferroxidase and ferric transporter genes of different pathogenic filamentous ascomycetes. Arrows show orientations of genes. C, Amino acid sequence alignment of the two putative ferroxidases CgFet3-1 and CgFet3-2 of Colletotrichum graminicola with that of the S. cerevisiae ferroxidase ScFet3. The copper-binding motifs are indicated by solid circles; the four homologous elements common to the fungal ferroxidases sequences are denoted by boxes 1 to 4 ; transmembrane domain is denoted by a dotted box. Solid triangles show putative $\mathrm{Fe}^{+2}$-binding ligands. 
in maize, siderophore-mediated iron uptake rather than RIA plays the predominant role in virulence (Greenshields et al. 2007; Oide et al. 2006; Park et al. 2006). Also in other necrotrophs, including Cochliobolus heterostrophus, the causal agent of southern corn leaf blight fungus, Cochliobolus miyabeanus, the causal agent of brown spot disease in rice, and Alternaria brassicicola, causing black spot disease on virtually all economically important Brassica spp., secretion of siderophores is required for full virulence (Oide et al. 2006).

The maize anthracnose and stalk rot fungus Colletotrichum graminicola (teleomorph: Glomerella graminicola) is a filamentous ascomycete displaying a hemibiotrophic lifestyle (Bergstrom and Nicholson 1999; Horbach et al. 2011; O'Connell et al. 2012). On the plant surface, this pathogen differentiates a dome-shaped, melanized infection cell, called an appressorium. The appressorium generates enormous turgor pressure of 50 to $60 \mathrm{bar}$ in order to breach the cuticle and wall of the epidermal host cell (Bechinger et al. 1999). Inside of the host cell, biotrophic infection vesicles and primary hyphae are formed. At this stage of infection, the host cell is viable (Bergstrom and Nicholson 1999). Biotrophic hyphae invaginate and are encased by the plasma membrane of the host and, thus, are located in a bifacial matrix, which likely represents an environment extremely poor in iron. Thus, formation not only of germ tubes and appressoria on the plant cuticle but also of biotrophic hyphae likely occurs under extreme iron limitation, indicating that high-affinity iron uptake systems are indispensable during these early stages of pathogenesis. At later stages, the fungus differentiates thin, fast-growing secondary hyphae. To gain access to the intracellular nutrients, including minerals, pathogenic hyphae breach the plasma membrane, kill the plant cells, and, therefore, are referred to as necrotrophic hyphae. In comparison with appressoria and biotrophic hyphae, necrotrophic hyphae are likely not exposed to extreme iron limitation. Thus, as in hemibiotrophs like $C$. graminicola, biotrophic and necrotrophic hyphae are sequentially formed, this fungus allows study of the role of RIA during pathogenesis and, moreover, discrimination between the importance of this high-affinity iron uptake pathway in different pathogenic lifestyles.

In $C$. graminicola, we identified and functionally characterized the two ferroxidase genes FET3-1 and FET3-2. While FET3-1 is strongly expressed during development on the plant surface and in biotrophic hyphae, it is not significantly expressed in necrotrophic infection structures. Significant levels of FET3-2 transcripts have not been detected during pathogenesis. On intact maize leaves, $\Delta$ fet $3-1$ and $\Delta$ fet $3-1 / 2$ doubledeletion strains showed reduced rates of germination and formation of appressoria and biotrophic hyphae, and the occurrence of disease symptoms was significantly delayed. On wounded leaves, where only necrotrophic secondary hyphae are formed, $\Delta$ fet $3-1$ strains showed only marginally reduced virulence, suggesting that RIA is required for appressorial penetration, biotrophy, or both. Surprisingly, appressorial cell wall integrity was severely affected in $\Delta f e t 3-1$ and $\Delta f e t 3-1 / 2$ double-deletion strains, phenocopying mutants of the myosin motor domain chitin synthase CHSV (Werner et al. 2007). Indeed, transcript abundance of $C H S V$ was dramatically reduced. Thus, this study shows a link between RIA and cell wall integrity.

\section{RESULTS}

\section{Identification and cloning}

of ferroxidase genes of $\boldsymbol{C}$. graminicola.

The genome of $C$. graminicola contains two ferroxidase genes, which we designated as FET3-1 and FET3-2. The GenBank accession numbers are EFQ33392.1 and EFQ26799.1, respectively (Fig. 1A). The deduced amino acid sequence of the $C$. graminicola Fet3-1 protein revealed significant identity with ferroxidases of other filamentous ascomycetes such as $F$. graminearum (69\%), Botryotinia fuckeliana (67\%), and Aspergillus fumigatus (64\%). Fet3-2 showed $60 \%$ identity with the C. graminicola Fet3-1 protein and $60 \%$ identity with the ferroxidase FET5 of Magnaporthe oryzae. Fet3-2 of C. graminicola also showed high similarity with the corresponding ferroxidases of other filamentous ascomycetes (Fig. 1A). Like

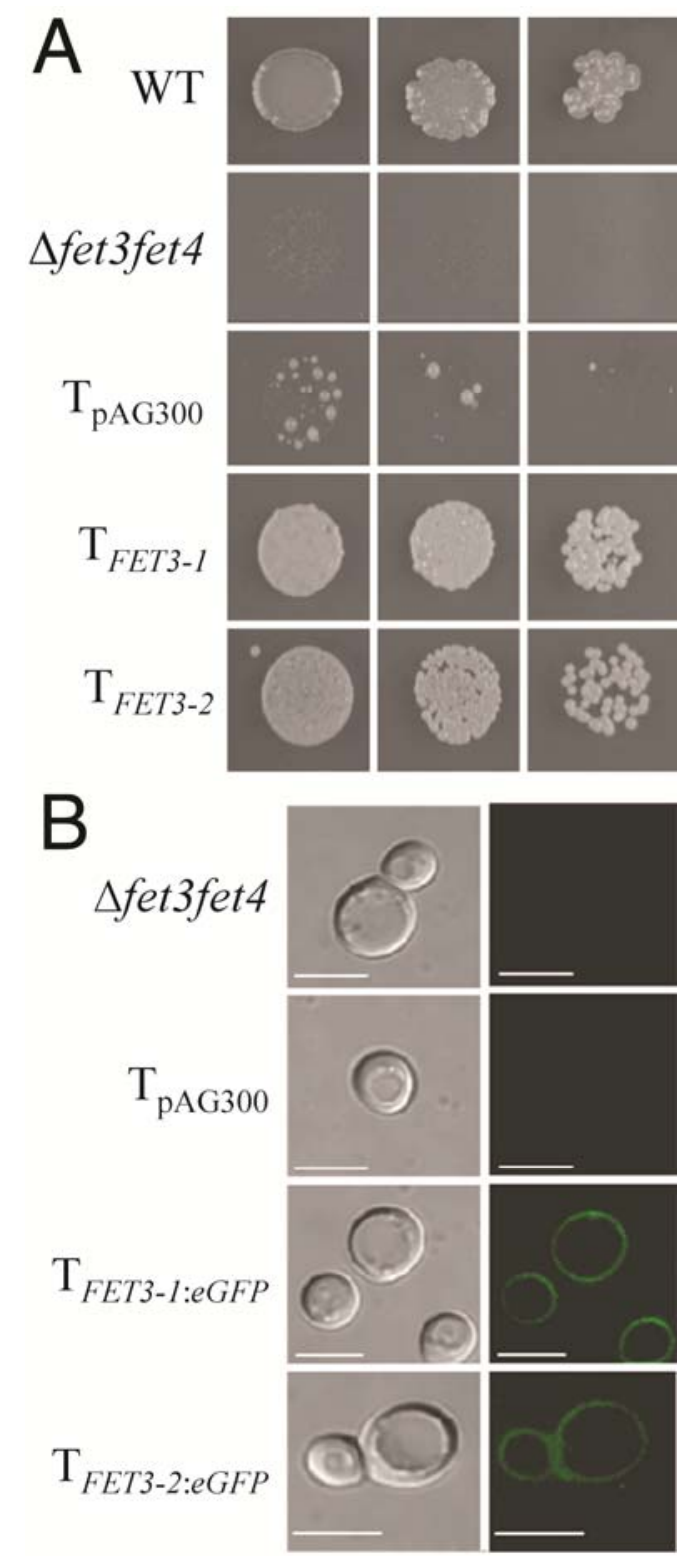

Fig. 2. Complementation of the Saccharomyces cerevisiae ferroxidase mutant fet3fet 4 by the Colletotrichum graminicola ferroxidase genes FET3-1 and FET3-2. A, S. cerevisiae (wild type [WT]) and yeast mutant $\Delta$ fet3fet 4 harboring the plasmids pAG300-FET3-1 ( $\left.\mathrm{T}_{\text {FET3-I }}\right)$, pAG300FET3-2 $\left(\mathrm{T}_{\text {FET3-2 }}\right)$, or the empty vector pAG300 $\left(\mathrm{T}_{\mathrm{pAG} 300}\right)$ were grown overnight in synthetic complete (SC) medium (ura ${ }^{-}$) containing $50 \mu \mathrm{M}$ bathophenanthroline disulfonate (BPS). A 10-fold dilution series was dotted onto solidified SC medium containing $50 \mu \mathrm{M}$ BPS and incubated for 4 days. The $\Delta$ fet 3 fet 4 was grown in SC medium and served as a control. B, To visualize the localization of Fet3-1 and Fet3-2 of $C$. graminicola, the yeast expression vector pAG300 harboring enhanced green fluorescent protein (eGFP) fusions of FET3-1 ( $\left.\mathrm{T}_{\text {FET3-1:eGFP }}\right)$ or FET3-2 $\left(\mathrm{T}_{\text {FET3-2:eGFP }}\right)$ were transformed into yeast mutant $\Delta$ fet 3 fet 4 . eGFP fluorescence can be seen in the plasma membrane of transformants $\mathrm{T}_{\text {FET3-1:eGFP }}$ and $\mathrm{T}_{\text {FET3-2:eGFP }}$. Bars $=5 \mu \mathrm{M}$. 
C. graminicola, the genomes of A. oryzae, $F$. graminearum, and Nectria haematococca contained two ferroxidases genes located in the direct vicinity of FTRI genes encoding ferric permeases (Fig.1B).

The ferroxidases of $C$. graminicola showed elements common to all fungal ferroxidases, i.e., four highly conserved boxes (Fig. 1C, boxes 1 to 4), a transmembrane domain (Fig. 1C, dotted box), four copper-binding motifs (Fig. 1C, solid circles), and a putative $\mathrm{Fe}^{2+}$ ligand-binding motif (Fig. 1C, solid triangles). This protein organization is in full agreement with that of ferroxidases of other fungi (Bonaccorsi di Patti et al. 2001; Kosman 2002; Wang et al. 2003).

To confirm that both Fet3-1 and Fet3-2 of C. graminicola represent functional ferroxidases, we performed complementation assays with the Saccharomyces cerevisiae $\Delta$ fet 3 fet 4 double mutant that shows growth defects under iron-limiting conditions (Askwith et al. 1994; Dix et al. 1994) (Fig. 2A). The $\Delta$ fet $3 f e t 4$ mutant is auxotroph for uracil and, therefore, unable to grow on synthetic complete (SC) medium lacking uracil and containing $50 \mu \mathrm{M}$ iron scavenger bathophenanthroline disulfonate (BPS) (SC + BPS). The $\Delta$ fet 3 fet 4 strain transformed with the empty transformation vector pAG300 (Fig. 2A, $\mathrm{T}_{\mathrm{pAG} 300}$ ), conferring uracil prototrophy, showed reduced growth on $\mathrm{SC}+$ BPS (Fig. 2, $\mathrm{T}_{\mathrm{pAG} 300}$ ). However, growth of $\Delta$ fet 3 fet 4 strains transformed with the expression vector pAG300 harboring either the FET3-1 or the FET3-2 gene of C. graminicola was not distinct from that of the wild-type (WT) yeast strain (Fig. 2A, compare the WT with $\mathrm{T}_{F E T 3-1}$ and $\mathrm{T}_{\text {FET3-2 }}$ ).

Different programs predicting subcellular protein localization (e.g., TMHMM Server v. 2.0, SOSUI, PRED-TMR, and DAS-TMfilter) identified a transmembrane domain of Fet3-1 (amino acids 553 to 575) and Fet3-2 (amino acids 556 to 578) and suggested that these ferroxidases are plasma membrane localized. To confirm the predicted plasma membrane localization of Fet3-1 and Fet3-2, enhanced green fluorescent protein (eGFP) fusions of Fet3-1 or Fet3-2 were expressed in S. cerevisiae $\Delta$ fet 3 fet 4 cells. As expected, in transformants $\mathrm{T}_{\text {FET3-1:eGFP }}$ and $\mathrm{T}_{F E T 3-2: e G F P}$, eGFP-tagged proteins localized to the plasma membrane (Fig. 2B; $\mathrm{T}_{\text {FET3-1:eGFP }}$ and $\mathrm{T}_{\text {FET3-2:eGFP }}$ ).

Taken together, these results show that FET3-1 and FET3-2 encode functional ferroxidases.

\section{Iron availability affects transcript abundance} of genes involved in reductive iron assimilation.

Using quantitative reverse-transcriptase polymerase chain reaction (qRT-PCR) analyses, we investigated the transcriptional response of RIA genes of $C$. graminicola to iron availability. Iron limitation was induced by adjusting the liquid growth
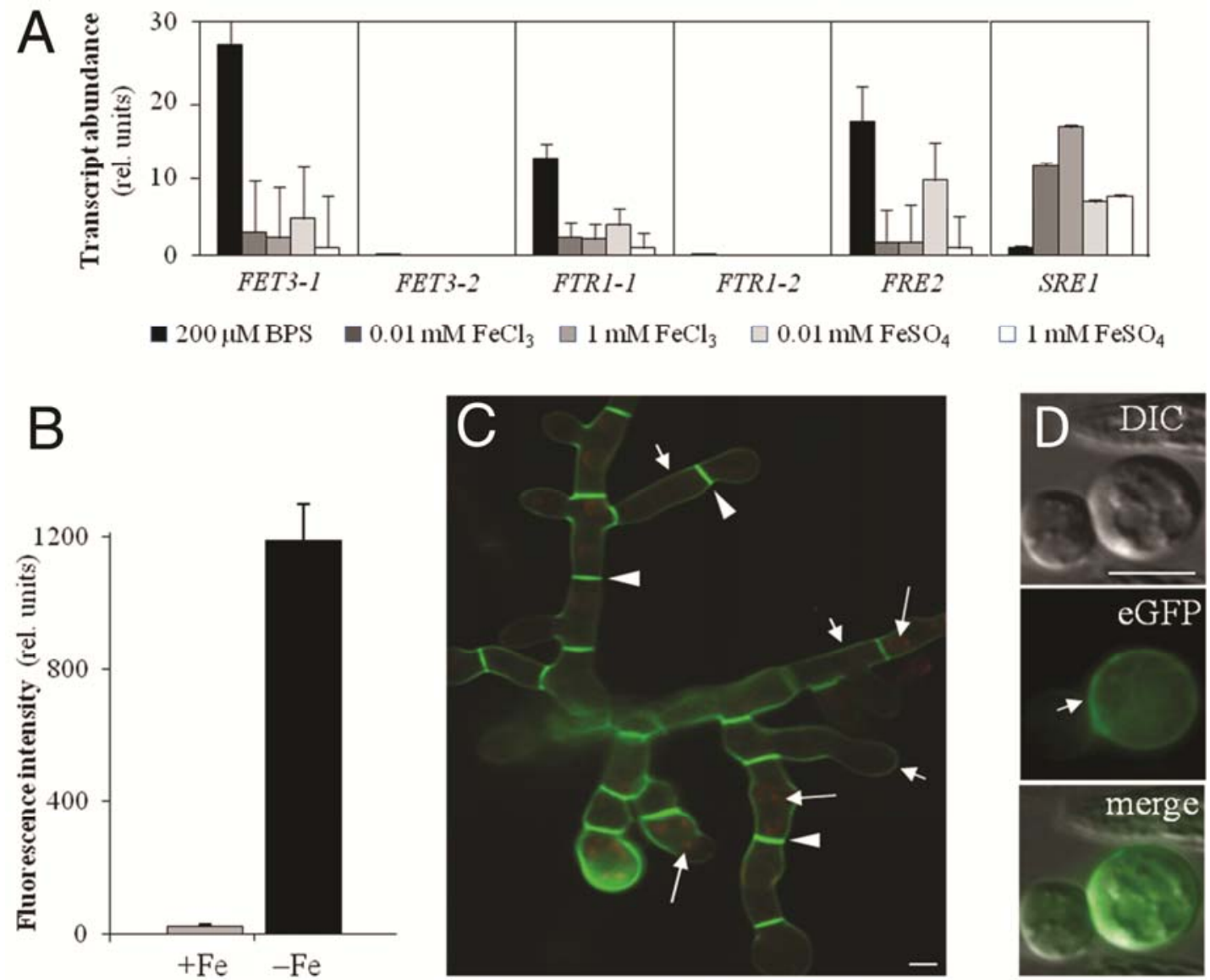

Fig. 3. Relative transcript abundance of iron-uptake-related genes and localization of Fet3-1 in Colletotrichum graminicola. A, Relative transcript abundance was measured by quantitative reverse-transcriptase polymerase chain reaction and is given in relative units. Actin $A C T 1$ and histone $H 3$ transcripts were used as reference. The transcript abundance of FET3-2 and FTR1-2 was not quantified, because the cycle threshold values of these transcripts were 53 and 50 cycles, respectively. B, Control of FET3-1 expression by the availability of iron, as measured by the enhanced green fluorescent protein (eGFP) fluorescence of the wild-type strain harboring the $\mathrm{P}_{\text {FET3-1 }}: e G F P$ fusion. Iron sufficiency $(+\mathrm{Fe})$ was established by addition of $100 \mu \mathrm{M}$ FeSO ${ }_{4}$, and iron limitation $(-\mathrm{Fe})$ was induced by adding the iron scavenger bathophenanthroline disulfonate to a concentration of $100 \mu \mathrm{M}$. Fluorescence intensity is given in relative units. Bars in A and B show +standard errors. C, eGFP fluorescence in plasma membranes (short arrows) of an FET3-1:eGFP strain of C. graminicola. eGFP fluorescence appears to be more intensive at septa (arrowheads). Red fluorescence (long arrows) indicates SynaptoRed (FM4-64)-stained intracellular, possibly vacuolar membranes. Bar $=5 \mu \mathrm{m}$. D, Protoplasts generated from an FET3-1:eGFP strain show eGFP fluorescence in the plasma membrane, indicating that eGFP fluorescence in $\mathrm{C}$ is not cell wall associated. $\mathrm{Bar}=5 \mu \mathrm{m}$. 
medium to contain $200 \mu \mathrm{M}$ BPS. FET3-1, the ferric transporter gene $F T R 1-1$, and the ferric reductase gene FRE2 showed significant transcript abundances under these conditions (Fig. 3A). In contrast, even when using total RNA amounts as high as $100 \mathrm{ng}$ in qRT-PCR assays, FET3-2 and FTR1-2 showed cycle threshold values of 53 and 50 cycles, respectively, and, therefore, their transcript abundance was too low for reliable quantification. However, in $\Delta f e t 3-1$ strains but not in the WT strain, low levels of FET3-2 transcripts were present, as shown by RT-PCR (Supplementary Fig. S1). Under iron-limiting conditions, as expected, transcripts of the GATA transcription factor SRE1, a putative repressor of genes involved in iron uptake (Chao et al. 2008; Haas, 2012), were present at low concentration. Increasing concentrations of $\mathrm{Fe}^{2+}$ or $\mathrm{Fe}^{3+}$ to 0.01 or $1 \mathrm{mM}$ decreased the transcript concentrations of FET3-1, FTR1-1, and FRE2 but increased transcript abundance of SRE1. At low concentrations of $\mathrm{FeSO}_{4}$, the transcript concentration of FRE2 was only reduced by approximately $50 \%$, possibly due to the fact that $\mathrm{Fe}^{2+}$ is not a substrate of ferric reductase. Transcript abundance of the SRE1 gene increased with increasing concen- trations of available iron. Like FRE2, SRE1 had a stronger response to $\mathrm{Fe}^{3+}$ than to $\mathrm{Fe}^{2+}$ (Fig. 3A).

The iron-dependent expression of FET3-1 was further studied, taking advantage of a strain harboring eGFP directly fused to the FET3-1 promoter $\left(\mathrm{P}_{\text {FET3-1 }}\right)$. This strain displays a colony phenotype, pigmentation, sporulation, growth rates on potato dextrose agar (PDA), and virulence comparable to the WT strain. In this strain, the intensity of eGFP fluorescence was approximately 1,200 -fold higher in the presence of $100 \mu \mathrm{M}$ BPS than in medium containing $100 \mu \mathrm{M} \mathrm{FeSO}$ (Fig. 3B). These data fully support qRT-PCR measurements showing that iron limitation increased the transcript abundance of FET3-1 (Fig. 3A). In order to visualize the localization of FET3-1, a FET3-1:eGFP fusion construct was transformed into a $\triangle$ fet $3-1$ deletion strain. The transformants harboring the FET3-1:eGFP construct did not differ from the WT strain with respect to colony phenotype, pigmentation, sporulation, and growth rates on PDA. Importantly, the FET3-1:eGFP construct fully complemented the virulence defect of the $\Delta$ fet $3-1$ deletion strain (Supplementary Fig. S3), indicating that function and localization

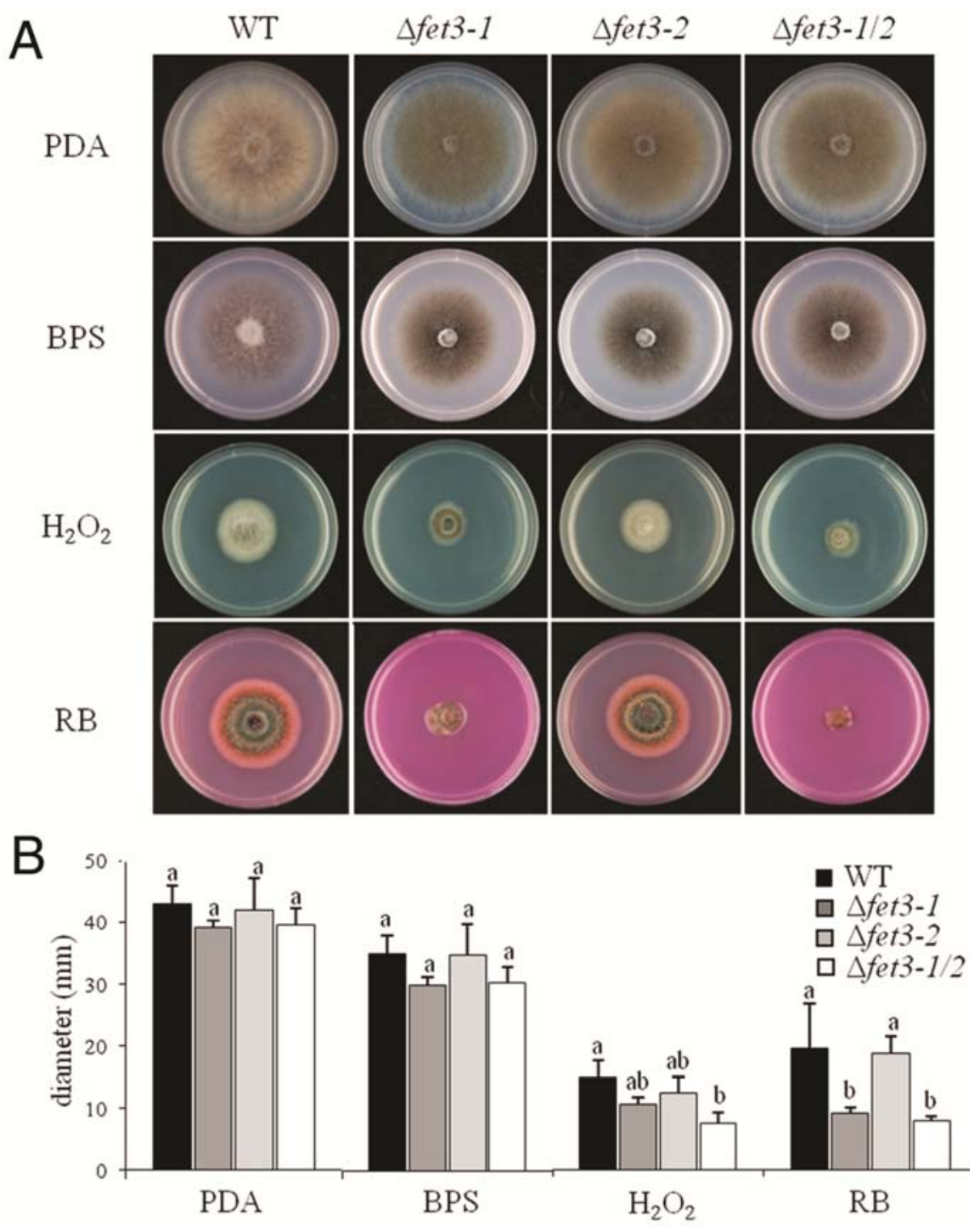

Fig. 4. Growth assays with the wild type (WT) and the ferroxidase mutants $\Delta$ fet3-1, $\Delta$ fet3-2, and $\Delta$ fet $3-1 / 2$. A, Growth and colony phenotype of the WT and ferroxidase mutants $\Delta$ fet $3-1, \Delta$ fet $3-2$, and $\Delta$ fet3-1/2 on potato dextrose agar (PDA), PDA containing $100 \mu \mathrm{M}$ bathophenanthroline disulfonate (BPS), 0.01\% $\mathrm{H}_{2} \mathrm{O}_{2}\left(\mathrm{H}_{2} \mathrm{O}_{2}\right)$, or the singlet oxygen-generator rose bengal (RB) at $100 \mu \mathrm{g} / \mathrm{ml}$. No differences between WT and mutants were observed under iron-limiting conditions but $\Delta$ fet3-1 and $\Delta$ fet3-1/2 showed reduced growth in the presence of reactive oxygen species. Photos have been taken at 4 days postinoculation (DPI) (PDA, BPS, and $\mathrm{H}_{2} \mathrm{O}_{2}$ ) and 13 DPI (RB). B, Quantitative growth assays showing that reactive oxygen species but not iron limitation significantly affects growth of ferroxidase mutants. Different letters represent significance groups at $P=0.001, n=4$. Bars show standard deviation. Growth rate has been measured 4 DPI (PDA, BPS, and $\mathrm{H}_{2} \mathrm{O}_{2}$ ) and 13 DPI (RB). 
of the Fet3-1:eGFP fusion protein resembled that of the Fet3-1 protein. Microscopic analyses of a strain expressing the FET3-1: $e G F P$ fusion construct under control of the native $\mathrm{P}_{\text {FET3-1 }}$ promoter showed that Fet3-1 localized to hyphal plasma membranes (Fig. 3C, short arrows), with major fluorescence visible at the septa of vegetative hyphae (Fig. 3C, arrowheads). The strong fluorescence signal in septa may be due to two membranes of neighboring cells sandwiching the septum.

Plasma membrane localization of FET3-1 was further confirmed by protoplasting of vegetative hyphae of FET3-1:eGFP strains grown under iron-limiting conditions. In agreement with the yeast complementation experiments described above (Fig. 2), eGFP fluorescence was visible in the plasma membrane of the protoplasts of $C$. graminicola (Fig. 3D, arrow). Staining of vacuolar membranes with the red fluorescing styryl dye FM4-64 clearly indicated that Fet3-1 does not localize to the vacuole or vacuolar membrane (Fig. 3C, long arrows).

Attempts to localize the Fet3-2 protein by generating strains harboring a FET3-2:eGFP construct failed, due to low expression of this gene.

These data indicate that the availability of extracellular iron regulates the genes involved in RIA in $C$. graminicola and show that Fet3-1 is a plasma-membrane-localized protein.

\section{The ferroxidase Fet3-1 of $C$. graminicola contributes to tolerance to ROS but is not required for vegetative growth under iron-limiting conditions.}

To functionally characterize the ferroxidase genes FET3-1 and FET3-2 of $C$. graminicola, targeted gene deletion was performed. FET3-1 and FET3-2 were replaced by the nourseothricin acetyl transferase (nat1) (Malonek et al. 2004) and the hygromycin phosphotransferase (hph) (Horbach et al. 2009) genes, respectively. Furthermore, the FET3-2 gene was also deleted in the $\Delta f e t 3-1$ background, leading to $\Delta f e t 3-1 / 2$ double-deletion strains. Successful deletion of FET3-1 and FET3-2 and homologous integration of the resistance cassettes was confirmed by Southern hybridization (Supplementary Fig. S2).

Growth assays with the $\Delta$ fet $3-1, \Delta f e t 3-2$ and $\Delta$ fet $3-1 / 2$ strains on PDA and PDA amended with $100 \mu \mathrm{M}$ BPS showed no significant difference between these deletion strains and the WT strain CgM2 (Fig. 4). These data indicate that RIA is not required for iron uptake during vegetative growth.
Because generation of ROS contributes to the prime defense responses of plants, and because iron plays an important role in quenching of ROS, we investigated whether RIA is required for tolerance to ROS in C. graminicola. Both $\mathrm{H}_{2} \mathrm{O}_{2}$ and singlet oxygen formed on illuminated plates amended with rose bengal strongly reduced growth rates of $C$. graminicola. $\Delta$ fet $3-1$ and $\Delta$ fet $3-1 / 2$ strains showed clearly increased sensitivity to both rose bengal and $\mathrm{H}_{2} \mathrm{O}_{2}$, without major differences between the $\Delta f e t 3-1$ and $\Delta f e t 3-1 / 2$ strains. The $\Delta f e t 3-2$ strains did not differ from the WT strain. Thus, FET3-1 but not FET3-2 is required for tolerance to ROS in vegetative hyphae. Interestingly, neither the transcript abundance of FET3-1 nor that of FET3-2 was affected by the addition of $\mathrm{H}_{2} \mathrm{O}_{2}$ to the growth medium, indicating that a link between ROS-mediated membrane distortion and iron uptake does not exist in C. graminicola (Supplementary Fig. S4).

\section{Reductive iron assimilation is required}

for cell wall integrity and full virulence of $C$. graminicola.

Ferroxidases represent pathogenicity factors in the biotrophic maize smut fungus $U$. maydis (Eichhorn et al. 2006) but not in necrotrophic fungi (Greenshields et al. 2007; Oide et al. 2006; Schrettl et al. 2004). However, the importance of RIA for virulence of hemibiotrophs is unknown. In order to investigate whether the two ferroxidases identified in $C$. graminicola are required for virulence in this hemibiotroph and, if so, whether they are required during biotrophic or necrotrophic development, deletion mutants were employed in pathogenicity assays (Fig. 5).

The WT, the single-deletion strains $\Delta f e t 3-1$ and $\Delta f e t 3-2$, and the double-deletion strain $\Delta f e t 3-1 / 2$ were inoculated onto intact and wounded maize leaves. On nonwounded leaves, the $\Delta$ fet $3-1$ and the $\Delta$ fet $3-1 / 2$ strains showed strongly retarded anthracnose disease symptom development compared with the WT strain (Fig. 5A). PCR-based quantification of the fungal mass in infected leaves at 4 days postinoculation (DPI) confirmed that the $\Delta f e t 3-1$ strain was significantly less virulent than the WT strain (Fig. 5B). On wounded leaves, C. graminicola did not differentiate biotrophic but only necrotrophic infection hyphae. On wounded leaves, $\Delta$ fet $3-1$ strains showed virulence comparable with the WT strain, suggesting that FET3-1 is required for appressorial penetration, biotrophic development, or both. Furthermore, on wounded leaves, the dif-
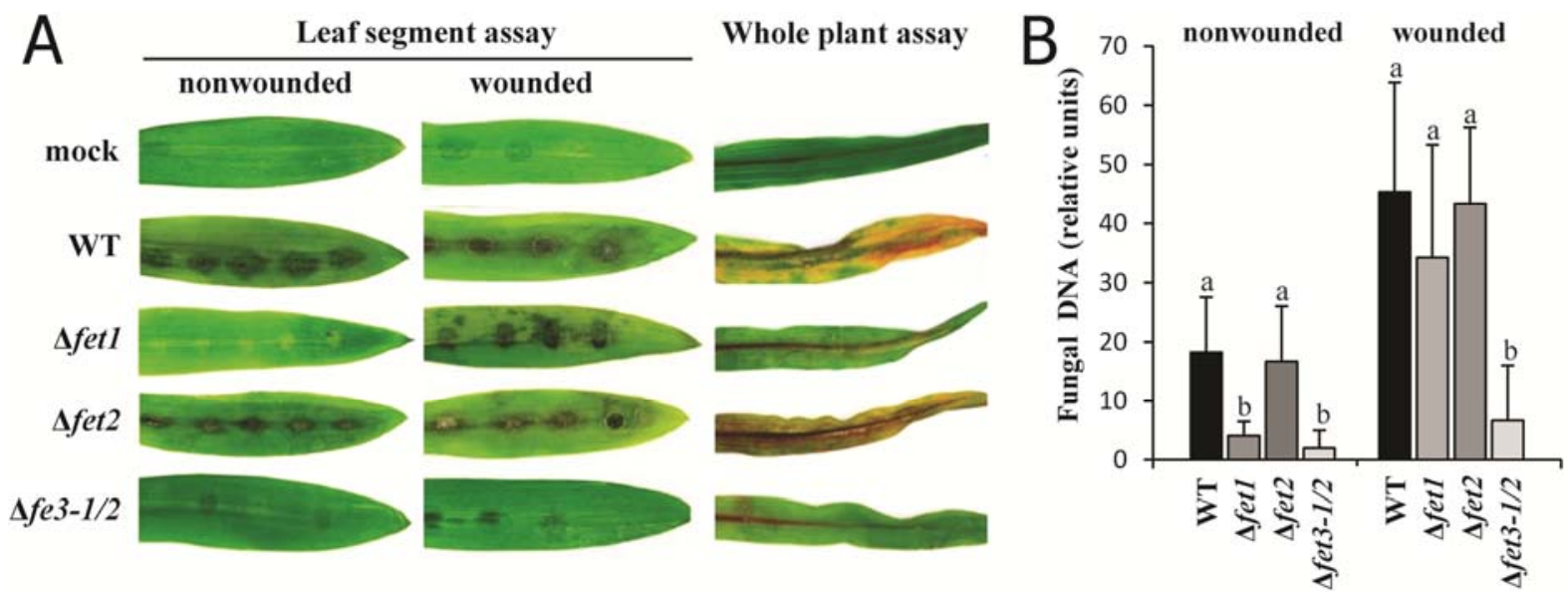

Fig. 5. Virulence assay of the ferroxidase mutants $\Delta f e t 3-1, \Delta f e t 3-2$, and $\Delta f e t 3-1 / 2$ compared with the Colletotrichum graminicola wild-type (WT) strain on nonwounded and wounded maize leaf segments and whole plants. A, On nonwounded leaves, the WT and the $\Delta$ fet $3-2$ strains caused severe anthracnose disease symptoms; $\Delta f e t 3-1$ and $\Delta f e t 3-1 / t 2$ strains caused minor disease symptoms only. On wounded leaf segments $\Delta$ fet $3-1$ strains caused symptoms comparable with the WT strain. Infection assays on nonwounded whole plants confirmed results with nonwounded leaf segments. Mock-inoculated leaves (mock) did not show symptoms. Photos were taken 4 days postinoculation (DPI) of maize 'Nathan' inoculated with $10^{4}$ conidia per spot. B, Quantitative polymerase chain reaction-based quantification of genomic DNA of $C$. graminicola in nonwounded and wounded maize leaves inoculated with the WT strain and $\Delta$ fet3-1, $\Delta f e t 3-2$, and $\Delta f e t 3-1 / 2$ strains. Samples were taken at 4 DPI. Different letters represent significance groups at $P \leq 0.001$, and bars $=+$ standard deviation; $n=3$. 
ferences in virulence between the $\Delta f e t 3-1$ the $\Delta f e t 3-1 / 2$ strain became more obvious. The $\Delta f e t 3-1 / 2$ strain caused significantly reduced disease symptom severity on wounded leaves (Fig. 5A and B). Virulence defects of $\Delta f e t 3-1$ and $\Delta f e t 3-1 / 2$ strains were visible not only on leaf segments but also on whole plants (Fig. 5A).

Microscopic inspection of infection sites revealed that conidia of the WT and $\Delta f e t 3-2$ strains had germinated and formed appressoria on the maize leaf surface at $24 \mathrm{~h}$ postinoculation (HPI) (Fig. 6A, WT and $\Delta$ fet3-2; co and ap). Whereas 75 and $79 \%$ of the conidia of the WT and $\Delta f e t 3-2$ strains, respectively, had germinated at $24 \mathrm{HPI}$, germination rates of $\Delta$ fet $3-1$ (approximately $25 \%$ ) and $\Delta$ fet $3-1 / 2$ (approximately $35 \%$ ) strains were clearly reduced (Fig. 6B). Interestingly, in contrast to conidia of the WT and $\Delta$ fet3-2 strains, which formed single or, rarely, two germ tubes, conidia of $\Delta f e t 3-1$ and $\Delta f e t 3-1 / 2$ strains often formed multiple germ tubes (Fig. 6A, $24 \mathrm{HPI}, \Delta$ fet $3-1$ and $\Delta f e t 3-1 / 2$, inserts, arrowheads). At $24 \mathrm{HPI}, 63$ and $65 \%$ of the conidia of the WT and $\Delta f e t 3-2$ strains, respectively, had formed appressoria, 98.5 and $98 \%$ of which had melanized. In comparison, at that time, only 12 and $27 \%$ of the conidia of $\Delta f e t 3-1$ and $\Delta f e t 3-1 / 2$ strains, respectively, had differentiated appressoria, and 50 and $75 \%$ of the appressoria of these strains were nonmelanized (Fig. 6A [24 HPI, ap] and B). Thus, compared with the WT and $\Delta f e t 3-2$ strains, appressorium formation and melanization were severely delayed in $\Delta$ fet $3-1$ and $\Delta f e t 3-1 / 2$ strains (Fig. 6B). Intriguingly, hyphae of $\Delta f e t 3-1$ and $\Delta f e t 3-1 / 2$ strains growing on the plant surface showed cell wall defects, as indicated by formation of hyphal protrusions (Fig. 6A, $24 \mathrm{HPI} ; \Delta$ fet $3-1$ and $\Delta$ fet $3-1 / 2$, arrows).

At $48 \mathrm{HPI}$, the WT and $\Delta f e t 3-2$ strains had invaded the host leaf and formed biotrophic primary and necrotrophic secondary hyphae (Fig. 6A, $48 \mathrm{HPI}, \mathrm{WT}$ and $\Delta f e t 3-2$, sh). At this time point, many appressoria of $\Delta f e t 3-1$ and $\Delta f e t 3-1 / 2$ strains had also melanized but melanization appeared to be weaker than in the WT and $\Delta f e t 3-2$ strains (Fig. 6A, $48 \mathrm{HPI}$; $\Delta f e t 3-1$, ap). Appressoria of these strains often failed to penetrate the host and formed lateral germ tubes on the cuticle (Fig. 6A, $48 \mathrm{HPI}$; $\Delta$ fet3-1, lgt). At $48 \mathrm{HPI}$, only approximately 13 and $1 \%$ of the appressoria of $\Delta f e t 3-1$ and $\Delta f e t 3-1 / 2$ strains, respectively, had
A
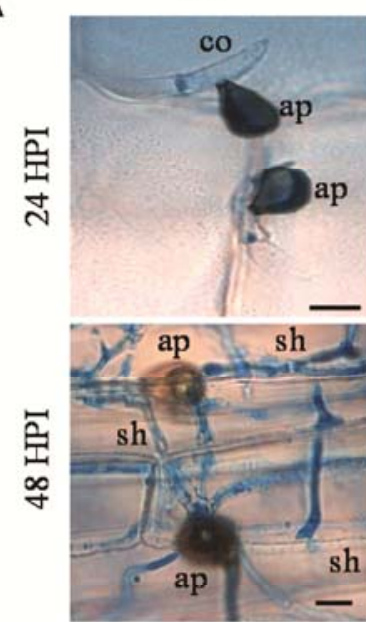

$\Delta f e t 3-1$

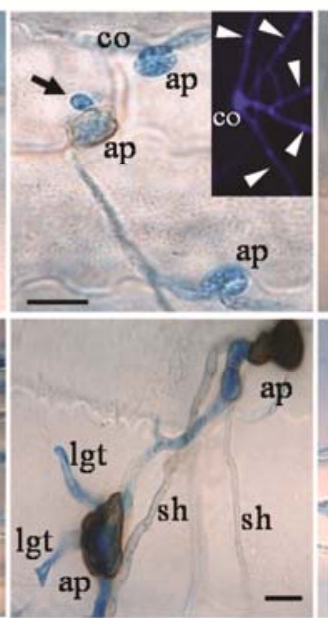

$\Delta f e t 3-2$

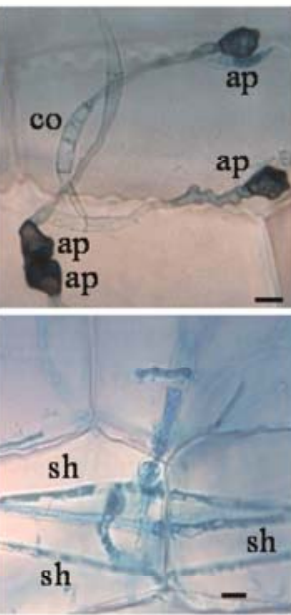

$\Delta f e t 3-1 / 2$

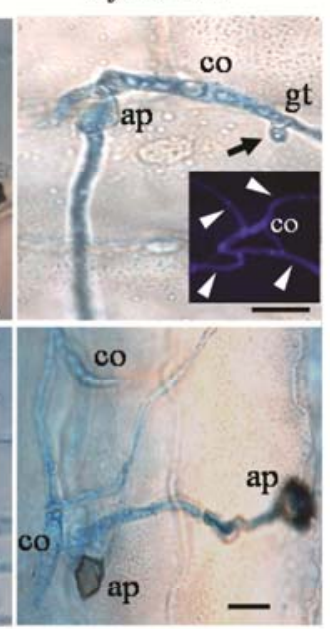

B

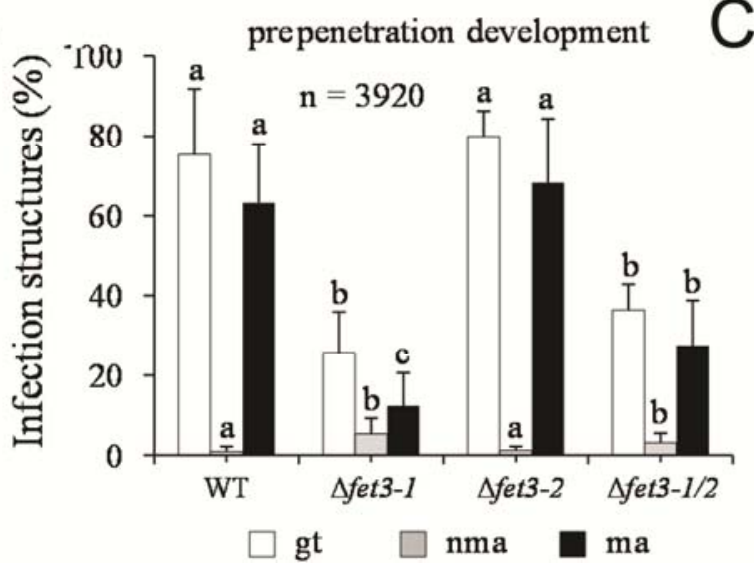

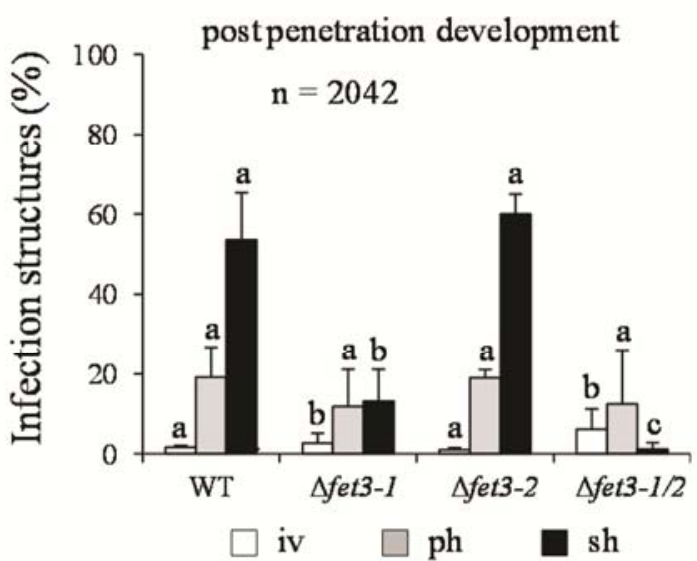

Fig. 6. Microscopic analysis of the infection process of the Colletotrichum graminicola wild-type (WT) and ferroxidase-deficient deletion strains. A, At $24 \mathrm{~h}$ postinoculation (HPI), conidia (co) of the WT and $\Delta f e t 3-2$ strains had germinated and differentiated melanized appressoria (ap). At this time, $\Delta f e t 3-1$ and $\Delta$ fet3-1/2 strains had formed nonmelanized appressoria (ap), and germ tubes (gt) showed protrusions indicative of cell wall defects (arrow). Remarkably, conidia of these strains formed several germ tubes (insert, white arrowheads). At $48 \mathrm{HPI}$, the WT and $\Delta f e t 3-2$ strains had massively colonized the host tissue and formed necrotrophic secondary hyphae (sh). At this time, $\Delta$ fet $3-1$ strains had also formed some secondary hyphae, which derived from melanized appressoria (ap). Appressoria also formed lateral germ tubes (lgt) on the plant surface. Double-deletion strain $\Delta$ fet3-1/2 had also formed appressoria but secondary hyphae were rarely observed. Infection structures were stained by aniline blue or calcofluor (inserts). Bars $=10 \mu \mathrm{m}$. B, Quantification of prepenetration infection structures at $24 \mathrm{HPI}$ revealed that, compared with the WT and the $\Delta$ fet $3-2$ strains, $\Delta$ fet $3-1$ and $\Delta f e t 3-1 / 2$ strains showed reduced germination and appressorium differentiation rates. Several of these appressoria were nonmelanized. Abbreviations: gt, germ tube; nma, nonmelanized appressoria; ma, melanized appressoria. C, Quantification of post-penetration infection structures at 48 HPI revealed that in planta development of the WT and $\Delta f e t 3-2$ strains occurred rapidly, leading to large numbers of secondary hyphae. In contrast, formation of secondary hyphae was clearly reduced in $\Delta f e t 3-1$ strains and almost absent in $\Delta$ fet3-1/2 strains. Different letters in B and C represent significance groups between strains for each infection structure at significance level $P \leq 0.001$. Bars represent + standard deviation. Three replicates of 100 infection sites of the WT and three individual mutants have been counted. 
formed secondary necrotrophic hyphae, compared with approximately $55 \%$ of the WT and approximately $60 \%$ of the $\Delta$ fet3-2 strain (Fig. 6C).

To analyze the cell wall defects of $\Delta f e t 3-1$ strains in more detail, we depleted this strain and the WT strain for iron by precultivation on PDA in the presence of $100 \mu \mathrm{M}$ BPS for 14 days. Conidia of the WT strain (Fig. 7A, left micrograph) as well as those of $\Delta f e t 3-1$ (Fig. 7A, right micrograph) formed appressoria on maize leaves. Interestingly, appressoria of irondepleted $\Delta f e t 3-1$ strains had very thin cell walls and were nonmelanized (Fig. 7A, right micrograph, arrows), and several appressoria of these mutants ruptured spontaneously (Fig. 7A, right micrograph, long arrow). This phenotype resembles appressorial cell wall defects of class $\mathrm{V}$ chitin synthase mutants of $C$. graminicola previously described by Werner and associates (2007). The $\Delta f e t 3-1$ mutants also resembled $\Delta c h s V$ mutants with respect to their strongly impaired ability to breach the intact host surface and cause disease symptoms (Figs. 5 and 6). However, whereas iron-depleted $\Delta f e t 3-1$ mutants were unable to differentiate melanized appressoria on the surface of maize leaves, they were able to form alternative melanized infection cells called hyphopodia (Fig. 7A, right micrograph, insert) which is, again, in full agreement with $\Delta c h s V$ mutants (Werner et al. 2007). As expected, the iron-depleted WT strain formed melanized appressoria and hyphopodia on the leaf surface (Fig. 7A, left micrograph).

Because the $\Delta$ fet $3-1$ deletion strains represent a phenocopy of $\Delta c h s V$ mutants, we analyzed the transcript abundance of
$C H S V$ and, for comparison, the $\beta$-1,3-glucan synthase gene GLS1 in in vitro-differentiated appressoria of the WT strain and the ferroxidase mutant $\Delta$ fet $3-1$. Indeed, qRT-PCR analyses showed that $C H S V$ transcript abundance was dramatically reduced by approximately $80 \%$ in $\Delta f e t 3-1$ strains compared with the WT. Transcript abundance of GLS1 was only reduced by approximately $20 \%$ (Fig. 7B).

Increased sensitivity to cell-wall-degrading enzymes is a good indication for compromised cell wall integrity. As protoplasting efficiency cannot be quantified in vegetative hyphae, we incubated oval conidia with lyzing enzymes from Trichoderma harzianum (Werner et al. 2007). Indeed, oval conidia of $\Delta$ fet $3-1$ and $\Delta f e t 3-1 / 2$ strains were significantly more sensitive to lysing enzymes than those of the WT and $\Delta f e t 3-2$ strains. While $50 \%$ of the oval conidia of the WT and $\Delta f e t 3-2$ strains had protoplasted at approximately 4 and $3.8 \mathrm{~h}$, respectively, approximately 1.6 and $2.3 \mathrm{~h}$ were sufficient for protoplasting $50 \%$ of the conidia of the $\Delta f e t 3-1$ and $\Delta$ fet3-1/2 strains (Fig. 7C).

These results clearly show that $\Delta$ fet $3-1$ and $\Delta$ fet $3-1 / 2$ strains but not $\Delta f e t 3-2$ strains have significant cell wall defects.

\section{FET3-1 is differentially expressed during pathogenesis.}

Reduced rates of germination, appressorium formation, penetration of the host plant, and formation of primary hyphae in $\Delta$ fet $3-1$ and $\Delta f e t 3-1 / 2$ strains suggested that FET3- 1 is required for iron uptake during the early stage of infection (i.e., during prepenetration and biotrophic development) (Fig. 6). The role of FET3-1 in appressorial penetration or biotrophy was con-

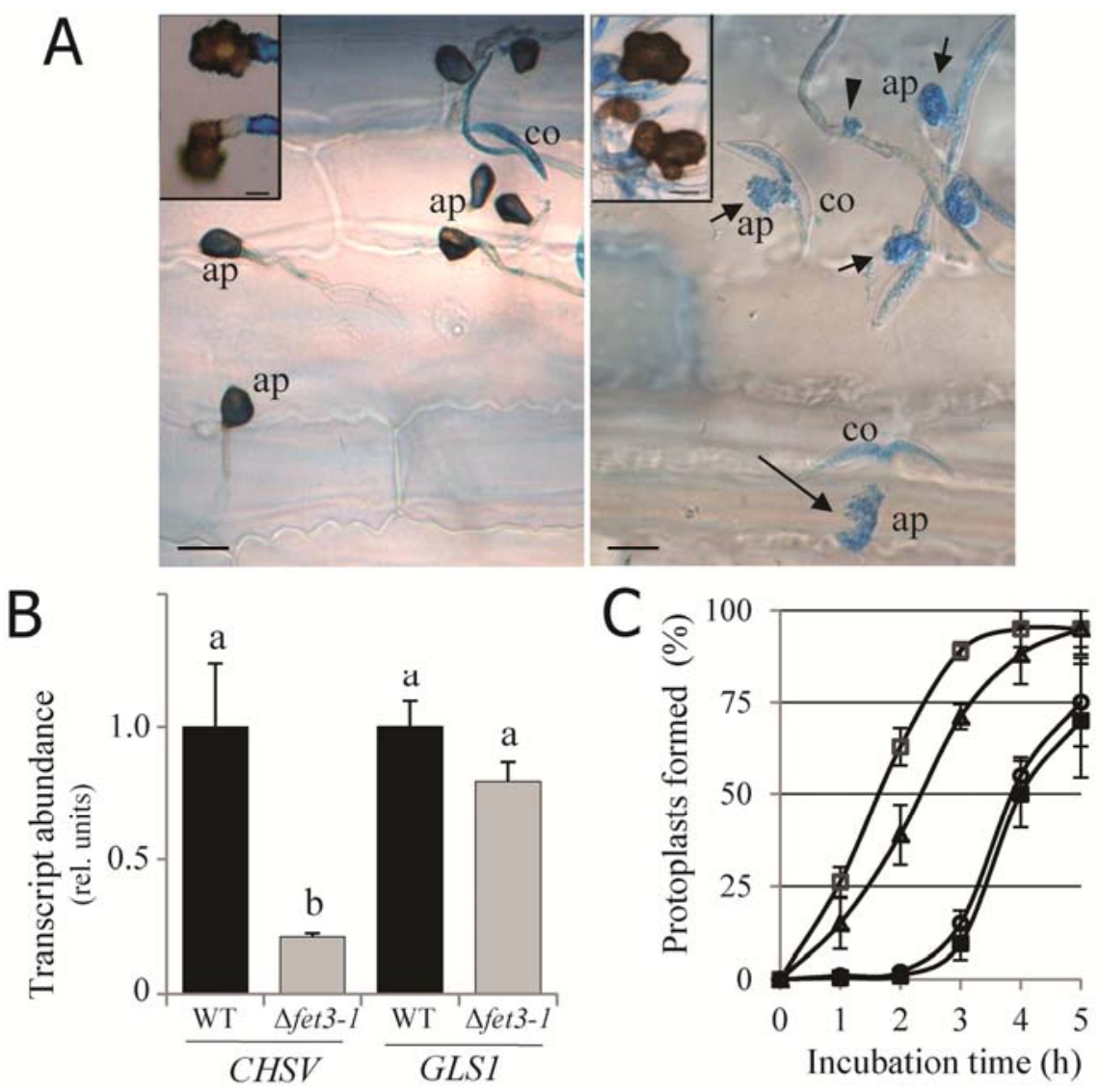

Fig. 7. The $\triangle f e t 3-1$ mutants exhibit severe cell wall defects and reduced $C H S V$ transcript abundance. A, Under severe iron limitation, conidia (co) of the wild-type (WT) strain (left panel) but not of $\Delta$ fet3-1 strains (right panel) are able to differentiate melanized appressoria (ap) on the maize cuticle. Appressoria of $\Delta$ fet3-1 strains have thin cell walls, are nonmelanized (right panel, short arrows), and often rupture (right panel, long arrow). Inserts show melanized hyphopodia. Bars = $10 \mu \mathrm{m}$. B, In appressoria of $\Delta f e t 3-1$ strains differentiated on polypropylene sheets, transcript abundance of the myosin-motor domain chitin synthase gene CHSV were significantly and those of the $\beta-1,3$-glucan synthase gene $G L S 1$ slightly reduced. Different letters indicate significant differences $(P \leq 0.001)$. Bars represent + standard deviation (SD). Three replicates of the WT and of three independent $\Delta f e t 3-1$ strains have been analyzed. C, Protoplasting efficiency assay show that oval conidia of $\Delta f e t 3-1$ (white squares) and $\Delta f e t 3-1 / 2$ (white triangles) strains release protoplasts much faster than those of the $\Delta f e t 3-2$ (white circles) and WT (black squares) strains. Three individual replicates have been counted of each strain, with 100 conidia each at each time point. Bars indicate \pm SD. 
firmed by comparative infection assays on nonwounded and wounded maize leaves (Fig. 5). Because infection structure differentiation and leaf colonization do not occur synchronously, RT-PCR experiments do not provide accurate information regarding at which stages of the infection process FET3-1 is expressed. Therefore, we decided to analyze FET3-1 expression in individual infection structures formed on maize leaves by monitoring eGFP expressed under the control of the FET3-1 promoter. Preliminary data had shown that virulence was not affected in strains harboring a $\mathrm{P}_{F E T 3-1}: e G F P$ construct. Significant eGFP fluorescence was observed in dormant and germinating conidia, in appressoria (Fig. 8A, 24 HPI, co and ap), and in
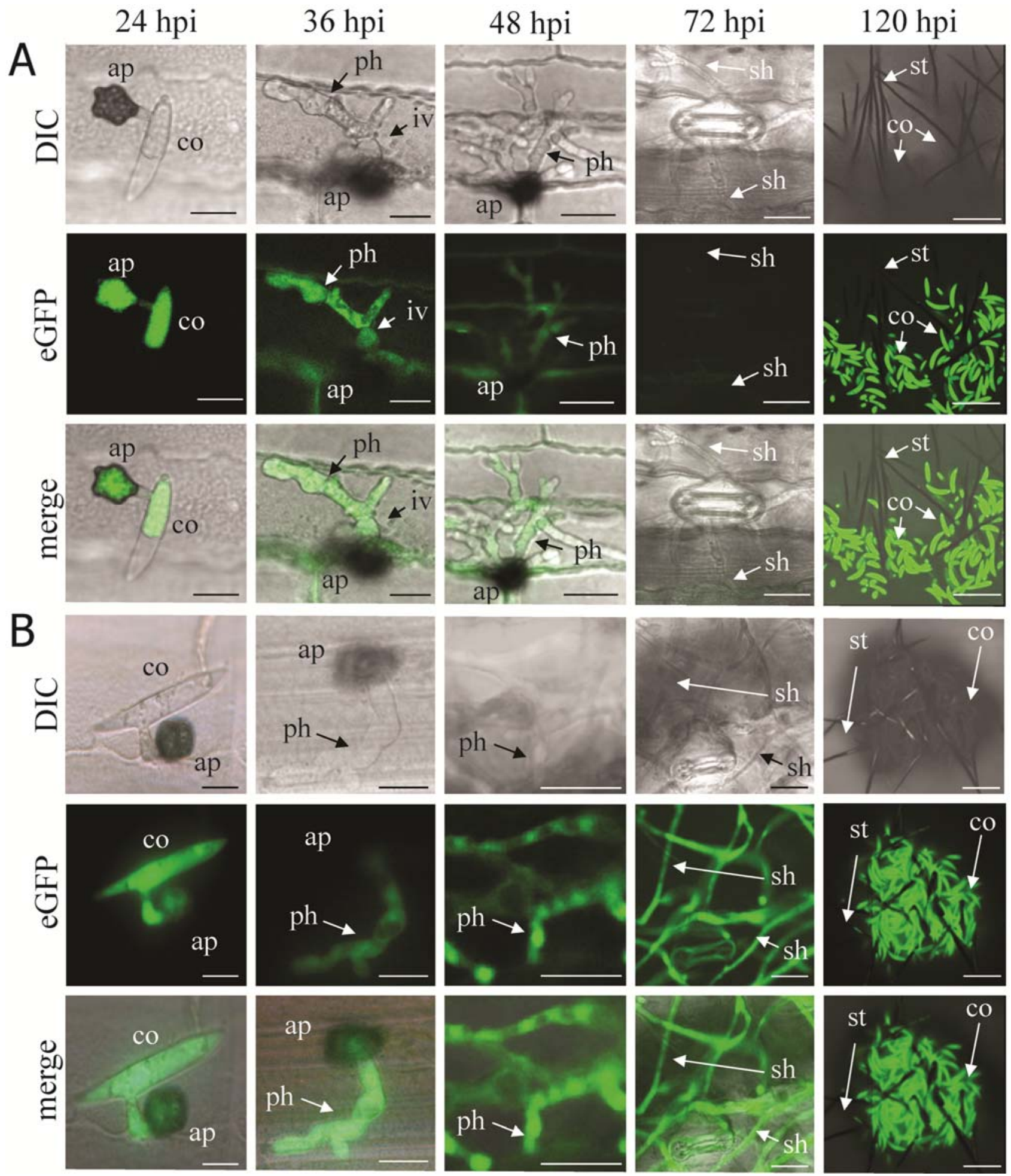

Fig. 8. Infection structure-specific expression of FET3-1. A, Expression of FET3-1 was assessed in a Colletotrichum graminicola replacement strain harboring a $\mathrm{P}_{\text {FET3-1: }}$ enhanced green fluorescent protein (eGFP) fusion construct at the infection structure-specific level. eGFP fluorescence was clearly visible in conidia (co) and appressoria (ap), as well as in biotrophic infection vesicles (iv) and primary hyphae (ph). In necrotrophic secondary hyphae (sh) representing the vast majority of infection structures at $72 \mathrm{~h}$ postinoculation (HPI), eGFP fluorescence was absent but reappeared in novel conidia formed at $120 \mathrm{HPI}$. B, In a strain expressing the $e G F P$ gene under the control of the constitutive ToxB promoter of Pyrenophora tritici-repentis, eGFP fluorescence was seen in all infection structures formed on and inside the host. DIC, differential interference contrast; st, sterigma. Bars: 24 and $36 \mathrm{HPI}=10 \mu \mathrm{m}, 48$ and $72 \mathrm{HPI}=20 \mu \mathrm{m}$, and $120 \mathrm{HPI}=50 \mu \mathrm{m}$. 
infection vesicles and primary hyphae (i.e., at the biotrophic stage of pathogenesis) (Fig. 8A, $36 \mathrm{HPI}$; iv and ph). At $48 \mathrm{HPI}$ (i.e., in late primary hyphae) (Fig. 8A, $48 \mathrm{HPI}$; ph), the intensity of eGFP fluorescence was reduced, had disappeared completely at $72 \mathrm{HPI}$ in necrotrophic secondary hyphae (Fig. 8A, $72 \mathrm{HPI}$; $\mathrm{sh}$ ), and stayed undetectable until the fungus had formed acervuli with new conidia at $120 \mathrm{HPI}$ (Fig. 8A, $120 \mathrm{HPI}$; co).

To demonstrate that eGFP fluorescence is detectable in necrotrophic secondary hyphae, the $e G F P$ reporter gene was also fused to the constitutive ToxB promoter of the wheat pathogen Pyrenophora tritici-repentis (Andrie et al. 2005). As expected, strains expressing the $\mathrm{P}_{T o x B}: e G F P$ fusion showed fluorescence in conidia and in all infection structures, including necrotrophic secondary hyphae (Fig. 8B), clearly demonstrating that downregulation of eGFP fluorescence in strains harboring the $\mathrm{P}_{\text {FET3-1 }}: e G F P$ construct is due to infection structure specificity of the $\mathrm{P}_{\text {FET3-1 }}$.

In summary, these data show that RIA is specifically required during those stages of pathogenesis when iron is available at extremely low concentrations (i.e., during development on the plant surface and during differentiation of biotrophic infection hyphae in the bifacial matrix).

\section{DISCUSSION}

Studying RIA in the hemibiotroph $C$. graminicola, we made two major discoveries. First, a central element of the RIA pathway, the ferroxidase-encoding gene FET3-1, is expressed infection structure specifically during development on the cuticle and during biotrophic development. Second, we showed a link between high-affinity iron uptake, transcriptional regulation of the class V chitin synthase gene $C H S V$, and cell wall integrity.

Iron is an indispensable element for virtually all organisms, including fungi. For plant-pathogenic fungi, iron likely represents a limiting factor not only on the leaf surface but also inside of the host tissue. This latter aspect may be of particular importance in biotrophic hyphae and in haustoria, which are located in the apoplast and are encased by the plant plasma membrane. Inside of the plant cells, iron is tightly bound by proteins such as ferritin, and sequestration of iron by the plant may reduce the availability of this redox element and have a prominent role in weakening virulence of fungal pathogens that breach the plasma membrane and invade the host cell. Indeed, in Arabidopsis thaliana reduced iron availability correlated with reduced disease severity of the necrotrophic fungus Botrytis cinerea (Kieu et al. 2012). In line with these observations, transgenic tobacco plants overexpressing the alfalfa $F E R$ gene, encoding an iron-binding ferritin, showed increased resistance to the necrotrophic fungal pathogens Alternaria alternata and B. cinerea (Deak et al. 1999). Not only in plants but also in animals, an iron withholding defense system exists. Here, processes activated in response to microbial attack include a rapid reduction of iron concentration in plasma, increased synthesis of macrophage ferritin, and release of apolactoferrin from neutrophil granules, leading to binding of iron in septic sites (Weinberg 2009). Interestingly, a screen of mutants of the opportunistic dimorphic fungus Candida albicans deficient in components of three iron uptake systems showed that RIA is involved in acquisition of iron from ferritin by invasive hyphae (Almeida et al. 2008). Intriguingly, transgenic wheat (Triticum aestivum) plants expressing a bovine lactoferrin cDNA showed that increased contents of this iron-binding protein significantly increased resistance against the head blight fungus $F$. graminearum (Han et al. 2012).

However, iron also plays an active role in plant defense. In wheat, iron is a central mediator linking three defense responses (i.e., localized cell wall appositions known as papillae, genera- tion of antimicrobial ROS, and ROS-mediated activation of defense genes expression), collectively leading to increased resistance to the powdery mildew fungus Blumeria graminis. After attack of wheat leaves by $B$. graminis, targeted iron redistribution occurs, with reactive $\mathrm{Fe}^{3+}$ but not $\mathrm{Fe}^{2+}$ accumulating at cell wall appositions to mediate the oxidative burst (Liu et al. 2007). Thus, iron is required not only for growth and development of plants but also for coordinating defense responses.

Therefore, utilization of high-affinity iron uptake systems such as RIA or siderophore-mediated iron acquisition pathways by fungal pathogens likely serves two functions: i) supply of iron to be used for fungal development and ii) weakening of the redox-based pathogen defense systems of the host.

In this article, we showed for the first time that the hemibiotroph Colletotrichum graminicola activates the high-affinity RIA system at the early stage of fungal infection (i.e., during prepenetration and biotrophic development), and infection assays clearly indicated that the central component of RIA, the ferroxidase gene FET3-1, is required for full virulence. While these data are in agreement with the role of RIA in virulence of the biotroph $U$. maydis (Eichhorn et al. 2006), siderophoremediated iron uptake, rather than RIA, appears to be required for virulence in necrotrophs (Greenshields et al. 2007; Haas et al. 2008; Hwang et al. 2008; Oide et al. 2006). In F. graminearum, the siderophore biosynthesis gene SID1 encoding L-ornithine-5-monooxygenase, an early siderophore-synthesizing enzyme, but not the ferroxidase gene FET3, is required for full virulence (Greenshields et al. 2007).

Thus far, it is unclear why RIA is important primarily in biotrophic and hemibiotrophic pathogens but not in necrotrophs. However, it is interesting to note that, in yeast, the $\mathrm{Km}$ value of the bipartite RIA system corresponds to $0.2 \mu \mathrm{M}$, whereas those for the two siderophore (ferrichrome)-bound iron transporters Arn1p and Sit1p/Arn3p correspond to 0.9 and $2.3 \mu \mathrm{M}$, respectively (Haas et al. 2008). Necrotrophs kill their host cells, likely gaining access to elevated iron concentrations, which likely are fully sufficient for siderophore-mediated iron uptake. In wound-inoculated leaves, $C$. graminicola does not differentiate biotrophic hyphae and directly forms necrotrophic secondary hyphae (Horbach et al. 2009). When $\Delta$ fet3-1 strains, which exhibit reduced virulence on intact leaves, were inoculated onto wounded leaves, no significant reduction of virulence was observed, indicating that, in $C$. graminicola, the high-affinity RIA pathway is primarily required during biotrophic stages of pathogenesis. These data suggest that employment of RIA is beneficial, compared with synthesis of siderophores, in an environment extremely limited in iron such as the bifacial matrix surrounding biotrophic hyphae.

Importantly, our study showed a link between high-affinity iron uptake, transcriptional regulation of $C H S V$, and cell wall integrity in $C$. graminicola. Severe cell wall defects occurred in appressoria of $\Delta f e t 3-1$ strains. The appressorial cell walls of $\Delta f e t 3-1$ strains disintegrated on the leaf surface and displayed a phenocopy of mutants deficient in a class $\mathrm{V}$ chitin synthase (Werner et al. 2007). Both $\Delta c h s V$ and $\Delta f e t 3-1$ deletion strains formed appressoria but the appressorial cell walls of the mutants were very thin and nonmelanized. Interestingly, in in vitro-differentiated appressoria of $\Delta f e t 3-1$ strains, the transcript abundance of $C H S V$ was dramatically decreased (Fig. 7B). Although a direct link between RIA-mediated iron uptake and cell wall defects has not been demonstrated thus far, it is important to note that expression of the RBT5 gene of the human pathogen Candida albicans is regulated by the iron-responsive GATA-like factor Sfulp (Mishra et al. 2011). RBT5 encodes a glycosylphosphatidylinositol-anchored protein required for cell wall integrity and, also in Colletotrichum graminicola, cell wall integrity genes such as $C H S V$ and others might be under the 
control of an iron-responsive GATA-like factor. Indeed, GATAbinding sites are present at two positions (-163 and -434$)$ of the $5^{\prime}$-noncoding region of $C H S V$ and at two positions ( -17 and -282 ) of the $5^{\prime}$-noncoding region of GLS1. Thus, control of cell wall biogenesis genes of $C$. graminicola by homologs of the GATA factor SreA, possibly in tight interplay with repressors like HapX as in Aspergillus fumigatus (Hortschansky et al. 2007), might be required for cell wall integrity of $C$. graminicola. As a matter of fact, one (-231) and two (-490 and -997) HapX-like binding sites exist in the $5^{\prime}$-noncoding regions of the CHSV and GLS1 genes, respectively, supporting this assumption. One may further speculate that, under iron limitation, the cell wall defects in $C$. graminicola may be conferred by erroneous regulation of cell wall biogenesis genes. Recent studies have demonstrated that, in A. fumigatus, the mitogen-activated protein kinase MpkA controls cell wall integrity, iron adaptation, and oxidative stress response (Jain et al. 2011; Valiante et al. 2009). Accordingly, in C. graminicola, extreme iron limitation in $\Delta$ fet 3 1 and $\Delta f e t 31 / 2$ strains on the plant surface may lead to activation of MpkA which, in turn, might activate a repressor of genes involved in cell wall biogenesis, eventually causing lysis of appressoria differentiated on the plant cuticle (Fig 7A, right micrograph) (Jain et al. 2011).

In conclusion, we have shown for the first time that highaffinity reductive iron assimilation is infection structure specifically regulated and that a link exists between iron acquisition, biogenesis of the structural cell wall polymer chitin, and virulence. This study could stimulate the search for novel lead structures of iron-binding chemicals, to be used as antifungal compounds (Niewerth et al. 2003).

\section{MATERIALS AND METHODS}

\section{Strains, media, and culture conditions.}

The WT strain CgM2 of C. graminicola (Ces.) G. W. Wilson (teleomorph Glomerella graminicola D. J. Politis) was provided by R. L. Nicholson, Purdue University, IN, U.S.A. The CgM2 strain and $\Delta f e t 3-1$ and $\Delta f e t 3-2$ strains were grown on oat meal agar (OMA) (Werner et al. 2007). Alternatively, strains were grown in liquid complete medium (CM) (Leach et al. 1982) in an incubation shaker (Unitron; Infors AG, Bottmingen, Switzerland) at $23^{\circ} \mathrm{C}$ and $100 \mathrm{rpm}$. The double-deletion mutant $\Delta$ fet 3 $1 / 2$ was kept on OMA medium supplemented with $100 \mu \mathrm{M} \mathrm{Fe}$ (III)-EDTA (Duchefa, Haarlem, The Netherlands).

Sensitivity to ROS was determined on PDA (Becton Dickinson $\mathrm{GmbH}$, Heidelberg, Germany) supplemented with $0.01 \%$ (vol/vol) $\mathrm{H}_{2} \mathrm{O}_{2}$ (Carl Roth, Karlsruhe, Germany) in darkness or with rose bengal at $100 \mu \mathrm{g} / \mathrm{ml}$ under constant light $(20 \mu \mathrm{E}$ $\mathrm{m}^{-2} \mathrm{~s}^{-1}$ ) at $23^{\circ} \mathrm{C}$.

Iron-limiting conditions were introduced by adding $100 \mu \mathrm{M}$ iron chelator BPS (GFS Chemicals, Inc., Powell, OH, U.S.A.) to PDA.

Yeast SC medium contained $0.67 \%$ (wt/wt) yeast nitrogen base without amino acids (Becton Dickinson $\mathrm{GmbH}$ ), 2\% glucose, amino acids as required, and $1.8 \%$ (wt/wt) agar for solidified media (Carl Roth).

\section{Infection assays.}

Maize (14-day-old Zea mays 'Nathan'; KWS SAAT AG, Einbeck, Germany) plants were used in infection assays as described (Horbach et al. 2009). Leaf segments of the second and third fully expanded leaf were inoculated with $10-\mu$ d droplets containing $10^{4}$ conidia and $0.02 \%$ ( vol/vol) Tween 20 . To inoculate wounded leaves, five pricks were inserted, using sterican hypodermic needles $(0.4$ by $20 \mathrm{~mm}$; Braun, Melsungen, Germany) immediately before inoculation. Leaf segments ( 8 to $10 \mathrm{~cm}$ ) were placed into sealed petri dishes (diameter $9 \mathrm{~cm}$ ) containing two layers of moist filter paper and incubated in darkness at $28^{\circ} \mathrm{C}$ for $24 \mathrm{~h}$, followed by incubation at $25^{\circ} \mathrm{C}$. Symptoms were photographed at 4 DPI. Inoculation of whole plants was done as described (Behr et al. 2010).

qPCR was employed for quantifying the fungal mass of infection sites (F. Weihmann and S. G. R. Wirsel, personal communication). Briefly, eight detached third fully expanded leaves of 14-day-old maize plants per repetition and time point were inoculated, in which each leaf segment received a single $10-\mu l$ droplet containing $1 \times 10^{4}$ conidia on the central vascular bundle in the middle of the segment. Infected areas were collected at 4 DPI using a cork borer (diameter $0.6 \mathrm{~cm}$ ). qPCR was performed using primers ITS2-qPCR-Fw and ITS2-qPCR-Rv specific to the internal transcribed space region of rDNA of $C$. graminicola. Plasmid pUC18 (50 pg; Fermentas, St. Leon-Rot, Germany) was added at the beginning of DNA isolation as an external normalization reference. The pUC18 concentration was measured using primers M13-qPCR-Fw and M13-qPCR-Rv.

\section{Transcript abundance of genes involved in reductive iron assimilation and cell wall biogenesis.}

In order to induce iron starvation, mycelium of $C$. graminicola was grown in CM for 4 days, filtered through Miracloth (EMD Chemical, Darmstadt, Germany), washed three times with sterile deionized water (Milli-Q, TKA; Thermo Electron LED GmbH, Niederelbert, Germany), and transferred to iron free CM containing $50 \mu \mathrm{M}$ BPS for 2 days. Subsequently, the mycelium was transferred to fresh $\mathrm{CM}$ containing 0.01 or 1 $\mathrm{mM}$ ferric $\left(\mathrm{FeCl}_{3}\right)$ or ferrous $\left(\mathrm{FeSO}_{4}\right)$ iron, or 50 or $200 \mu \mathrm{M}$ BPS, for additional 2 days.

Total RNA was isolated using the PeqGOLD plant and fungal RNA kit (PEQLAB, Erlangen, Germany). Genomic DNA was removed using PeqGOLD DNase 1 Digest Kit (PEQLAB, Erlangen, Germany). qRT-PCR was performed using the Power SYBR Green RNA-to- $\mathrm{C}_{\mathrm{T}}$ 1-Step Kit (Applied Biosystems, Foster City, CA, U.S.A.), according to the instructions of the manufacturer. Gene-specific primers are listed in Supplementary Table S1. To confirm the absence of genomic DNA, RT-PCR and qRT-PCR assays were performed without reverse transcriptase. A sigmoidal curve fitting has been performed for all qRT-PCR analyses (Rutledge 2004), and relative transcript abundance has been quantified as described (Livak and Schmittgen 2001).

The relative transcript abundance has been normalized using the two constitutive housekeeping genes actin ACT1 and histone H3 (Behr et al. 2010; Horbach et al. 2009).

\section{Yeast complementation.}

The $S$. cerevisiae WT strain DY1457 (MAT $\alpha$, ade6, can1, his3, leu2, trp1, and ura3) and the mutant $\Delta$ fet3fet4 DEY1433 (MAT $\alpha$, ade2, can1, his3, leu2, trp1, ura3, fet3::HIS3, and fet4::LEU2) were used in this study. Both strains were provided by N. von Wirén, Leibniz Institute of Plant Genetics and Crop Plant Research (IPK), Gatersleben, Germany. C. graminicola FET3-1 and FET3-2 cDNA was amplified from mRNA isolated from the WT strain grown on CM containing $50 \mu \mathrm{M}$ BPS, using the Phusion RT-PCR Kit (New England Biolabs, County Road, Ipswich, England) and primer combinations FET3-1-SfiIA-Fw.1 and FET3-1-SfiIB-Rv.1, and FET3-2SfiIA-Fw.1 and FET3-2-SfiIB-Rv.1, respectively. The resulting cDNAs were cloned into pJET1.2/blunt (Fermentas). After confirming the sequences, the plasmids containing the cDNAs were digested with SfiI and subcloned into the SfiI-digested yeast expression plasmid pAG300 (Horbach et al. 2009), yielding pAG300-FET3-1 and pAG300-FET3-2. Thus, both cDNAs were expressed under the control of the constitutive ADH1 promoter (Vernet et al. 1987). Yeast WT and $\Delta$ fet 3 fet 4 
strains were transformed with pAG300, pAG300-FET3-1, or pAG300-FET3-2 using a standard protocol (Gietz and Woods 2002). To test for their capacity to take up iron, strains were plated out on SC medium containing $50 \mu \mathrm{M}$ BPS.

To visualize the localization of the Fet3-1 and Fet3-2 proteins, $e$ GFP fusions of FET3-1 and FET3-2 were generated, using double-joined PCR (Yu et al. 2004). cDNA of FET3-1 was amplified with primers FET3-1-SfiIA-Fw.1 and FET3-1eGFP-Rv.1, using pAG300 containing cDNA of FET3-1 as template. The cDNA of FET3-2 was amplified using primers FET3-2-SfiIA-Fw.1 and FET3-2-eGFP-Rv.1, and pAG300 containing cDNA of FET3-2 as template. The eGFP cassette was amplified with primers EGFP-Fw.1 and EGFP-SfiB-Rv.1 from plasmid pSH1.6EGFP, provided by A. Sharon, University of Tel Aviv, Israel. In a second PCR, the products of the first PCR were used to fuse the FET3-1 and the FET3-2 cDNAs with $e G F P$. These cassettes were digested with SfiI, ligated into SfiI-digested pAG300, and transformed into yeast mutant $\Delta$ fet3fet4.

All PCR were performed using Phusion High-Fidelity DNA Polymerases (New England Biolabs).

Targeted deletion of FET3-1 and FET3-2 of C. graminicola. Deletion cassettes were generated by double-joint PCR (Yu et al. 2004). The 5'- and 3'-flanking regions of the FET3-1 gene were amplified with the primer combinations FET3-1-KO-5' Fw.1 and FET3-1-KO-5'-Rv.1, and FET3-1-KO-3'-Fw.1 and FET3-1-KO-3'-Rv.1, and 100 ng of genomic DNA as template. The nat 1 cassette was amplified from plasmid pNR1 (Malonek et al. 2004), using primers Nat1-Fw.1 and Nat1-Rv.1. In a second PCR, the $5^{\prime}$ and $3^{\prime}$ flanks were fused with the nat 1 cassette, and the complete product was amplified using nested primers FET3-1-KO-nest.Fw.1 and FET3-1-KO-nest.Rv.1. The 4,167-bp product was cloned into pJET1.2/blunt, yielding plasmid pFET3-1KO.

To generate the FET3-2 deletion construct, the $5^{\prime}$ and $3^{\prime}$ flanks were amplified with the primer pairs FET3-2-KO-5'Fw.1 and FET3-2-KO-5'-Rv.1, and FET3-2-KO-3'-Fw.1 and FET3-2-KO-3'-Rv.1. The $h p h$ cassette was amplified from plasmid pAN7-1 (Punt et al. 1987) using primers Hyg-Fw.1 and Hyg-Rv.1. In a second PCR, the $5^{\prime}$ and $3^{\prime}$ flanks were fused with the $h p h$ cassette, and the complete product was amplified using nested primers FET3-2-KO-nest.Fw.1 and FET3-2-KO-nest.Rv.1. The 4,971-bp product was cloned into pJET1.2/blunt, yielding plasmid pFET3-2KO.

The FET3-1 and FET3-2 deletion constructs were amplified by PCR using pJET1.2-Fw and pJET1.2-Rv primers and transformed into conidial protoplasts as described (Werner et al. 2007).

All PCR were performed using Phusion High-Fidelity DNA Polymerases (New England Biolabs).

Generation of FET3-1:eGFP, FET3-2:eGFP, and promoter: $e G F P$ fusion constructs, and transformation into $C$. graminicola.

FET3-1:eGFP and FET3-2:eGFP fusions were produced by double-joined PCR (Yu et al. 2004). A PCR with the primer combination FET3-1-Fw.1 and FET3-1-eGFP-Rv.1 yielded a 2,992-bp fragment containing the FET3-1 open reading frame and $1,103 \mathrm{bp}$ of the $5^{\prime}$-flanking region. The promoterless $e G F P$ gene and the $h p h$ cassette were amplified from the $e G F P$ plasmid pSH1.6EGFP, using primers EGFP-Fw.1 and EGFP-Rv.1, yielded a 3,621-bp fragment containing the $e G F P$ gene, the gpdA promoter from A. nidulans, the hph gene of Escherichia coli, and the $\operatorname{trp} C$ terminator of $A$. nidulans. The FET3-1:eGFP construct and the $h p h$ cassette were then used as mega primers in a subseequent fusion PCR, and the com- plete product was amplified using nested primers FET3-1eGFP-nest-Fw.1 and FET3-1-eGFP-nest-Rv.1 and was cloned into plasmid pJET1.2/blunt (Fermentas), yielding the pFET31-eGFP-hyg plasmid.

The FET3-2:eGFP fusion cassette was generated as follows. The $e G F P$ cassette, containing the $e G F P$ gene and the trpC terminator from $A$. nidulans, was amplified from plasmid pSM1 (Pöggeler et al. 2003), using primers EGFP-Fw.2 and EGFP-Rv.2. The 1,645-bp geneticin-resistant cassette (G418), containing the neomycin phosphotransferase II gene (nptII) from transposon Tn5 (Beck et al. 1982), controlled by the $A$. nidulans trpC promoter and terminator, was amplified from the plasmid pII99 (Namiki et al. 2001) using the primer pair Gen-Fw.1 and Gen-eGFP-Rv.1. Both fragments were used as mega primers and fused to produce a 3,791-bp PCR fragment, which was cloned into pJET1.2/blunt cloning vector (Fermentas), yielding plasmid pJET-eGFP-G418. This plasmid was double digested with $N c o I$ and AgeI, yielding a 5,821-bp fragment. The 1,984-bp FET3-2 gene, including its 950-bp promoter region, was amplified using primers FET3-2-AgeI-Fw.1 and FET3-2-PciI-Rv.1, containing AgeI and PciI restriction sites. After purification of the resulting 2,955-bp FET3-2 PCR fragment, it was double digested using AgeI and PciI, and the 2,941-bp AgeI/PciI fragment was ligated into plasmid pJETeGFP-G418, which was double digested with the same enzymes in the frame with eGFP. The resulting plasmid pFET3-2eGFP-G418 was sequenced and used as a template for PCR.

To fuse $\mathrm{P}_{F E T 3-1}$ directly to $e G F P$, primers FET3-1-Fw.1 and FET3-1-eGFP-Rv.2 and genomic DNA of $C$. graminicola were used to amplify a 1,103-bp fragment (base pairs $-1,100$ to +3 ) of the $5^{\prime}$ region of FET3-1. The eGFP gene and the $h p h$ cassette were amplified from plasmid pSH1.6EGFP as described above, and the fragments were fused by joint PCR. Nested primers FET3-1-eGFP-nest-Fw.1 and FET3-1-eGFP-nest-Rv.1 were used to amplify a 4,693-bp fragment, which was cloned into plasmid pJET1.2/blunt (Fermentas), resulting in plasmid $\mathrm{P}_{\text {FET3-1 }}$-eGFP-hyg.

The FET3-1:eGFP, FET3-2:eGFP, and $\mathrm{P}_{\text {FET3-1 }}: e G F P$ constructs were amplified by PCR using primers pJET1.2-Fw and pJET1.2-Rv and transformed into conidial protoplasts as described (Werner et al. 2007).

All PCR were performed using Phusion High-Fidelity DNA Polymerases (New England Biolabs).

\section{DNA extraction and genomic Southern blot analyses.}

Extraction of genomic DNA from vegetative mycelium of $C$. graminicola was done as described (Döbbeling et al. 1997).

For Southern blot analyses, $5 \mu \mathrm{g}$ of genomic DNA was digested with PscI (FET3-1) or NcoI (FET3-2), separated on a $0.7 \%$ (wt/vol) agarose gel, depurinated, and blotted onto a positively charged nylon membrane (Hybond- $\mathrm{N}^{+}$; Amersham Pharmacia Biotech Europe, Freiburg, Germany) by downward alkaline capillary transfer (Brown 1999).

Digoxigenin-dUTP-labeled probes were generated by PCR using primers Nat1-Prob.Fw.1 and FET3-1-nest-Rv.3 and plasmid pFET3-1KO as template (FET3-1), or primers Hyg-probFw.1 and FET3-2-Rv.3 and plasmid pFET3-2KO (FET3-2). $\mathrm{Taq}$ polymerase was used for amplifying probes. Hybridization and probe detection was as described (Roche Diagnostics, Mannheim, Germany), and membranes were exposed to Hyperfilm ECL X-ray film (Amersham Pharmacia Biotech Europe).

\section{Protoplasting of oval conidia.}

Conidia from 10- to 14-day-old colonies grown on OMA plates were washed under sterile conditions using $1 \mathrm{ml}$ of $\mathrm{H}_{2} \mathrm{O}_{\text {bidest }}$, were inoculated into $100 \mathrm{ml}$ of $\mathrm{CM}$, and were adjusted to a final concentration of $10^{6}$ conidia/ml. The culture 
was incubated without shaking at room temperature for 6 to 8 days.

The culture was filtered through two layers of Miracloth (EMD Chemical), and the filtrate was centrifuged at 4,260 $\times g$ and $4{ }^{\circ} \mathrm{C}$ for $10 \mathrm{~min}$ to collect the oval conidia. The conidia were resuspended in a protoplasting solution containing lysing enzymes from Trichoderma harzianum (Sigma, Deisenhofen, Germany) at $20 \mathrm{mg} / \mathrm{ml} ; 0.1 \%$ (vol/vol) $\beta$-mercaptoethanol in $0.7 \mathrm{M} \mathrm{NaCl}$. The suspension was incubated at $30^{\circ} \mathrm{C}$ and 80 rpm (Unitron; Infors AG). Protoplasting efficiency was microscopically assessed every hour.

\section{Microscopy.}

Bright-field and differential interference contrast microscopy were performed using a Nikon Eclipse 90i microscope (Nikon, Düsseldorf, Germany) equipped with a DS-5M camera. Aniline blue and calcofluor-white staining was performed as described (De Neergaard 1997).

Fluorescence microscopy was performed, using a Nikon Eclipse 90i confocal laser-scanning microscope (Nikon), equipped with a D-Eclipse C1-SHV camera and a pinhole diameter of $30 \mu \mathrm{m}$. For detection of eGFP fluorescence, an excitation wavelength of $488 \mathrm{~nm}$ and a 535/550-nm detection channel were employed.

For FM4-64 staining (SynaptoRed; Sigma Aldrich, Munich, Germany), fungal mycelia were incubated in SynaptoRed at 5 $\mu \mathrm{g} / \mathrm{ml}$ in $\mathrm{CM}$ for $30 \mathrm{~min}$ at $28^{\circ} \mathrm{C}$. Mycelia were then washed with distilled water and incubated in CM containing $100 \mu \mathrm{M}$ BPS for $0,0.3,2,4$, and 8 h. FM4-64 fluorescence was detected using an excitation wavelength of $633 \mathrm{~nm}$ and the 650 LP detection channel.

Fluorescence intensity was measurement using the EZ-C1 software (Nikon). To quantify fluorescence, sterile microscopy slides were covered with a thin layer of $1 \%$ agarose (Biozym Diagnostik, Oldendorf, Germany), inoculated with $50 \mu \mathrm{l}$ of a suspension containing 10,000 conidia of $\mathrm{P}_{\text {FET3-1 }}$ e $e$ GFP strains in potato dextrose (PD) medium and inoculated overnight at $23^{\circ} \mathrm{C}$. The slides were then washed three times with deionized $\mathrm{H}_{2} \mathrm{O}$ and growing mycelia were further incubated for $24 \mathrm{~h}$ in PD supplemented with either $100 \mu \mathrm{M} \mathrm{FeSO}_{4}$ or $100 \mu \mathrm{M}$ BPS.

Image processing was done with Adobe Photoshop CS (Adobe Systems Inc., San Jose, CA, U.S.A.) or LSM imaging software (Carl Zeiss, Jena, Germany).

\section{Bioinformatic and prediction tools.}

The evolutionary relationship of Fet 3 proteins was analyzed using the Minimum Evolution method (Rzhetsky and Nei 1992). The bootstrap consensus tree was inferred from 1,000 replicates (Felsenstein 1985). Phylogenetic analyses were conducted in MEGA4 (Tamura et al. 2007).

To predict transmembrane domains, different prediction programs (i.e., TMHMM Server v. 2.0, SOSUI, PRED-TMR, and DAS-TMfilter) were used.

Calculation and statistical analysis of differences between groups were made using the one-way analysis of variance test, followed by the Holm-Sidak test at a freedom degree $(P<$ 0.001) (Sigma Plot v.11; Systat Software, Erkrath, Germany).

\section{ACKNOWLEDGMENTS}

This work was funded by the Interdisciplinary Center of Crop Plant Research (Interdisziplinäres Zentrum für Nutzpflanzenforschung, grant number Kap.00602, TG 68, project 10). E. Albarouki was supported, in part, by the German Academic Exchange Service (DAAD, grant number A/05/55302). We thank N. von Wirén and F. Ye, IPK Gatersleben, Germany, for stimulating discussions and providing yeast strains DY1457 and DEY1433; A. Sharon, University of Tel Aviv, Israel, for providing plasmid pSH1.6EGFP; B. Tudzynski, University of Münster, Germany, for provid- ing plasmid pNR1; F. Weihmann, Stefan G. R. Wirsel, and J.-J. Krijger (Martin-Luther-University University Halle-Wittenberg, Germany) for help with fungal mass quantification and provision of the ToxB:eGFP strain; and A. Beutel, D. Jany, and E. Vollmer (Martin-Luther-University University Halle-Wittenberg, Germany) for skillful technical support.

\section{LITERATURE CITED}

Almeida, R.S., Brunke, S., Albrecht, A., Thewes, S., Laue, M., Edwards, J. E., Filler, S. G., and Hube, B. 2008. the hyphal-associated adhesin and invasin Als 3 of Candida albicans mediates iron acquisition from host ferritin. PLoS Pathog. 4:21. Published online.

Andrie, R. M., Martinez, J. P., and Ciuffetti, L. M. 2005. Development of ToxA and ToxB promoter-driven fluorescent protein expression vectors for use in filamentous ascomycetes. Mycologia 97:1152-1161.

Arosio, P., and Levi, S. 2002. Ferritin, iron homeostasis, and oxidative damage. Free Radic. Biol. Med. 33:457-463.

Askwith, C., Eide, D., Van Ho, A., Bernard, P. S., Li, L., Davis-Kaplan, S., Sipe, D. M., and Kaplan, J. 1994. The FET3 gene of S. cerevisiae encodes a multicopper oxidase required for ferrous iron uptake. Cell 76:403-410.

Bechinger, C., Giebel, K.-F., Schnell, M., Leiderer, P., Deising, H. B., and Bastmeyer, M. 1999. Optical measurements of invasive forces exerted by appressoria of a plant pathogenic fungus. Science 285:18961899.

Beck, E., Ludwig, G., Auerswald, E. A., Reiss, B., and Schaller, H. 1982. Nucleotide sequence and exact localization of the neomycin phosphotransferase gene from transposon Tn5. Gene 19:327-336.

Behr, M., Humbeck, K., Hause, G., Deising, H. B., and Wirsel, S. G. 2010. The hemibiotroph Colletotrichum graminicola locally induces photosynthetically active green islands but globally accelerates senescence on aging maize leaves. Mol. Plant-Microbe Interact. 23:879-892.

Bergstrom, G. C., and Nicholson, R. L. 1999. The biology of corn anthracnose. Plant Dis. 83:596-608.

Bonaccorsi di Patti, M. C., Paronetto, M. P., Dolci, V., Felice, M. R., Lania, A., and Musci, G. 2001. Mutational analysis of the iron binding site of Saccharomyces cerevisiae ferroxidase Fet3. An in vivo study. FEBS (Fed. Eur. Biochem. Soc.) Lett. 508:475-478.

Brown, T. 1999. Southern blotting. Pages 2.9.1-2.9.15. in: Current Protocols in Molecular Biology. F. M. Ausubel, R. Brent, R. E. Kingston, D. D. Moore, J. G. Seidman, J. A. Smith, and K. Struhl, eds. John Wiley \& Sons, New York.

Chao, L. Y., Marletta, M. A., and Rine, J. 2008. Sre1, an iron-modulated GATA DNA-binding protein of iron-uptake genes in the fungal pathogen Histoplasma capsulatum. Biochemistry 47:7274-7283.

Deak, M., Horvath, G. V., Davletova, S., Torok, K., Sass, L., Vass, I., Barna, B., Kiraly, Z., and Dudits, D. 1999. Plants ectopically expressing the iron-binding protein, ferritin, are tolerant to oxidative damage and pathogens. Nat. Biotechnol. 17:192-196.

De Neergaard, E. 1997. Methods in botanical histopathology. Danish Government Institute of Seed Pathology for Developing Countries (DGISP). Copenhagen, Denmark.

Dix, D. R., Bridgham, J. T., Broderius, M. A., Byersdorfer, C. A., and Eide, D. J. 1994. The FET4 gene encodes the low affinity Fe(II) transport protein of Saccharomyces cerevisiae. J. Biol. Chem. 269:26092-26099.

Döbbeling, U., Boni, R., Haffner, A., Dummer, R., and Burg, G. 1997. Method for simultaneous RNA and DNA isolation from biopsy material, culture cells, plants and bacteria. Biotechniques 22:88-90.

Eichhorn, H., Lessing, F., Winterberg, B., Schirawski, J., Kämper, J., Muller, P., and Kahmann, R. 2006. A ferroxidation/permeation iron uptake system is required for virulence in Ustilago maydis. Plant Cell 18:3332-3345.

Eide, D. 1997. Molecular biology of iron and zinc uptake in eukaryotes. Curr. Opin. Cell Biol. 9:573-577.

Expert, D. 1999. Withholding and exchanging iron: Interactions between Erwinia spp. and their plant hosts. Annu. Rev. Phytopathol. 37:307-334.

Felsenstein, J. 1985. Confidence limits on phylogenies: An approach using the bootstrap. Evolution 39:783-791.

Gietz, R. D., and Woods, R. A. 2002. Transformation of yeast by lithium acetate/single-stranded carrier DNA/polyethylene glycol method. Methods Enzymol. 350:87-96.

Greenshields, D. L., Liu, G., Feng, J., Selvaraj, G., and Wei, Y. 2007. The siderophore biosynthetic gene SID1, but not the ferroxidase gene FET3, is required for full Fusarium graminearum virulence. Mol. Plant Pathol. 8:411-421.

Haas, H. 2003. Molecular genetics of fungal siderophore biosynthesis and uptake: The role of siderophores in iron uptake and storage. Appl. Microbiol. Biotechnol. 62:316-330.

Haas, H. 2012. Iron-A key nexus in the virulence of Aspergillus fumigatus. Front. Microbiol. 3:6. 
Haas, H., Eisendle, M., and Turgeon, B. G. 2008. Siderophores in fungal physiology and virulence. Annu. Rev. Phytopathol. 46:149-187.

Halliwell, B., and Gutteridge, J. M. 1984. Oxygen toxicity, oxygen radicals, transition metals and disease. Biochem. J. 219:1-14.

Halliwell, B., and Gutteridge, J. M. 1992. Biologically relevant metal iondependent hydroxyl radical generation. An update. FEBS (Fed. Eur. Biochem. Soc.) Lett. 307:108-112.

Han, J., Lakshman, D. K., Galvez, L. C., Mitra, S., Baenziger, P. S., and Mitra, A. 2012. Transgenic expression of lactoferrin imparts enhanced resistance to head blight of wheat caused by Fusarium graminearum. BMC Plant Biol. 12:1471-2229.

Hidalgo, E., Ding, H., and Demple, B. 1997. Redox signal transduction via iron-sulfur clusters in the SoxR transcription activator. Trends Biochem. Sci. 22:207-210.

Horbach, R., Graf, A., Weihmann, F., Antelo, L., Mathea, S., Liermann, J. C., Opatz, T., Thines, E., Aguirre, J., and Deising, H. B. 2009. Sfp-type $4^{\prime}$-phosphopantetheinyl transferase is indispensable for fungal pathogenicity. Plant Cell 21:3379-3396.

Horbach, R., Navarro-Quesada, A. R., Knogge, W., and Deising, H. B. 2011. When and how to kill a plant cell: Infection strategies of plant pathogenic fungi. J. Plant Physiol. 168:51-62.

Hortschansky, P., Eisendle, M., Al-Abdallah, Q., Schmidt, A.D., Bergmann, S., Thon, M., Kniemeyer, O., Abt, B., Seeber, B., Werner, E. R., Kato, M., Brakhage, A. A., and Haas, H. 2007. Interaction of HapX with the CCAAT-binding complex - a novel mechanism of gene regulation by iron. EMBO (Eur. Mol. Biol. Organ.) J. 26:3157-3168.

Hwang, L. H., Mayfield, J. A., Rine, J., and Sil, A. 2008. Histoplasma requires SID1, a member of an iron-regulated siderophore gene cluster, for host colonization. PLoS Pathog. 4:1000044. Published online.

Jain, R., Valiante, V., Remme, N., Docimo, T., Heinekamp, T., Hertweck, C., Gershenzon, J., Haas, H., and Brakhage, A. A. 2011. The MAP kinase MpkA controls cell wall integrity, oxidative stress response, gliotoxin production and iron adaptation in Aspergillus fumigatus. Mol. Microbiol. 82:39-53.

Jung, W. H., Hu, G., Kuo, W., and Kronstad, J. W. 2009. Role of ferroxidases in iron uptake and virulence of Cryptococcus neoformans. Eukarot. Cell 8:1511-1520.

Kieu, N. P., Aznar, A., Segond, D., Rigault, M., Simond-Cote, E., Kunz, C., Soulie, M. C., Expert, D., and Dellagi, A. 2012. Iron deficiency affects plant defence responses and confers resistance to Dickeya dadantii and Botrytis cinerea. Mol. Plant Pathol. 13:816-827.

Kosman, D. J. 2002. FET3P, ceruloplasmin, and the role of copper in iron metabolism. Adv. Protein Chem. 60:221-269.

Kosman, D. J. 2003. Molecular mechanisms of iron uptake in fungi. Mol. Microbiol. 47:1185-1197.

Leach, J., Lang, B. R., and Yoders, O. C. 1982. Methods for selection of mutants and in vitro culture of Cochliobolus heterostrophus. J. Gen. Microbiol. 128:1719-1729.

Liu, G., Greenshields, D. L., Sammynaiken, R., Hirji, R. N., Selvaraj, G., and Wei, Y. 2007. Targeted alterations in iron homeostasis underlie plant defense responses. J. Cell. Sci. 120:596-605.

Livak, K. J., and Schmittgen, T. D. 2001. Analysis of relative gene expression data using real-time quantitative PCR and the 2(-delta delta $\mathrm{C}(\mathrm{T})$ ) method. Methods 25:402-408.

Malonek, S., Rojas, M. C., Hedden, P., Gaskin, P., Hopkins, P., and Tudzynski, B. 2004. The NADPH-cytochrome P450 reductase gene from Gibberella fujikuroi is essential for gibberellin biosynthesis. J. Biol. Chem. 279:25075-25084.

Mishra, P. K., Baum, M., and Carbon, J. 2011. DNA methylation regulates phenotype-dependent transcriptional activity in Candida albicans. Proc. Natl. Acad. Sci. U.S.A. 108:11965-11970.

Namiki, F., Matsunaga, M., Okuda, M., Inoue, I., Nishi, K., Fujita, Y., and Tsuge, T. 2001. Mutation of an arginine biosynthesis gene causes reduced pathogenicity in Fusarium oxysporum f. sp. melonis. Mol. Plant-Microbe Interact. 14:580-584.

Neilands, J. B., Konopka, K., Schwyn, B., Coy, M., Francis, R., Paw, B H., and Bagg, A. 1987. Comparative biochemistry of microbial iron assimilation. Pages 3-34 in: Iron Transport in Microbes, Plants and Animals. G. Winkelmann, D. R. Winge, and J. B. Neilands, eds. VCH, Weinheim, Germany.

Niewerth, M., Kunze, D., Seibold, M., Schaller, M., Korting, H. C., and Hube, B. 2003. Ciclopirox olamine treatment affects the expression pattern of Candida albicans genes encoding virulence factors, iron metabolism proteins, and drug resistance factors. Antimicrob. Agents Chemother. 47:1805-1817.

O’Connell, R. J., Thon, M. R., Hacquard, S., Amyotte, S. G., Kleemann, J., Torres, M. F., Damm, U., Buiate, E. A., Epstein, L., Alkan, N., Altmuller, J., Alvarado-Balderrama, L., Bauser, C. A., Becker, C., Birren, B. W., Chen, Z., Choi, J., Crouch, J. A., Duvick, J. P., Farman, M. A., Gan, P.,
Heiman, D., Henrissat, B., Howard, R. J., Kabbage, M., Koch, C. Kracher, B., Kubo, Y., Law, A. D., Lebrun, M. H., Lee, Y. H., Miyara, I., Moore, N., Neumann, U., Nordstrom, K., Panaccione, D. G., Panstruga, R., Place, M., Proctor, R. H., Prusky, D., Rech, G., Reinhardt, R., Rollins, J. A., Rounsley, S., Schardl, C. L., Schwartz, D. C., Shenoy, N., Shirasu, K., Sikhakolli, U. R., Stuber, K., Sukno, S. A., Sweigard, J. A., Takano, Y., Takahara, H., Trail, F., van der Does, H. C., Voll, L. M., Will, I., Young, S., Zeng, Q., Zhang, J., Zhou, S., Dickman, M. B., SchulzeLefert, P., Ver Loren van Themaat, E., Ma, L. J., and Vaillancourt, L. J. 2012. Lifestyle transitions in plant pathogenic Colletotrichum fungi deciphered by genome and transcriptome analyses. Nat. Genet. 44:10601065

Oide, S., Moeder, W., Krasnoff, S., Gibson, D., Haas, H., Yoshioka, K., and Turgeon, B. G. 2006. NPS6, encoding a nonribosomal peptide synthetase involved in siderophore-mediated iron metabolism, is a conserved virulence determinant of plant pathogenic ascomycetes. Plant Cell 18:2836-2853.

Park, Y. S., Choi, I. D., Kang, C. M., Ham, M. S., Kim, J. H., Kim, T. H., Yun, S. H., Lee, Y. W., Chang, H. I., Sung, H. C., and Yun, C. W. 2006. Functional identification of high-affinity iron permeases from Fusarium graminearum. Fungal Genet. Biol. 43:273-282.

Philpott, C. C. 2006. Iron uptake in fungi: A system for every source. Biochim. Biophys. Acta 7:636-645.

Pöggeler, S., Masloff, S., Hoff, B., Mayrhofer, S., and Kuck, U. 2003. Versatile EGFP reporter plasmids for cellular localization of recombinant gene products in filamentous fungi. Curr. Genet. 43:54-61.

Punt, P. J., Oliver, R. P., Dingemanse, M. A., Pouwels, P. H., and van den Hondel, C. A. 1987. Transformation of Aspergillus based on the hygromycin B resistance marker from Escherichia coli. Gene 56:117-124.

Ramanan, N., and Wang, Y. 2000. A high-affinity iron permease essential for Candida albicans virulence. Science 288:1062-1064.

Ratledge, C., and Dover, L. G. 2000. Iron metabolism in pathogenic bacteria. Annu. Rev. Microbiol. 54:881-941.

Rutledge, R.G. 2004. Sigmoidal curve-fitting redefines quantitative realtime PCR with the prospective of developing automated high-throughput applications. Nucleic Acids Res. 32:e178. Published online.

Rzhetsky, A., and Nei, M. 1992. A simple method for estimating and testing minimum evolution trees. Mol. Biol. Evol. 9:945-967.

Schrettl, M., Bignell, E., Kragl, C., Joechl, C., Rogers, T., Arst, H. N., Jr., Haynes, K., and Haas, H. 2004. Siderophore biosynthesis but not reductive iron assimilation is essential for Aspergillus fumigatus virulence. J. Exp. Med. 200:1213-1219.

Shi, X., Stoj, C., Romeo, A., Kosman, D. J., and Zhu, Z. 2003. Fre1p Cu ${ }^{2+}$ reduction and $\mathrm{Fet} 3 \mathrm{p} \mathrm{Cu}{ }^{1+}$ oxidation modulate copper toxicity in Saccharomyces cerevisiae. J. Biol. Chem. 278:50309-50315.

Tamura, K., Dudley, J., Nei, M., and Kumar, S. 2007. MEGA4: Molecular Evolutionary Genetics Analysis (MEGA) software version 4.0. Mol. Biol. Evol. 24:1596-1599.

Valiante, V., Jain, R., Heinekamp, T., and Brakhage, A. A. 2009. The MpkA MAP kinase module regulates cell wall integrity signaling and pyomelanin formation in Aspergillus fumigatus. Fungal Genet. Biol. 46:909-918.

Vernet, T., Dignard, D., and Thomas, D. Y. 1987. A family of yeast expression vectors containing the phage $\mathrm{f} 1$ intergenic region. Gene 52:225-233.

Wang, T. P., Quintanar, L., Severance, S., Solomon, E. I., and Kosman, D. J. 2003. Targeted suppression of the ferroxidase and iron trafficking activities of the multicopper oxidase Fet $3 p$ from Saccharomyces cerevisiae. J. Biol. Inorg. Chem. 8:611-620.

Weinberg, E. D. 1978. Iron and infection. Microbiol. Rev. 42:45-66.

Weinberg, E. D. 2009. Iron availability and infection. Biochim. Biophys. Acta 7:600-605.

Welinder, K. G. 1992. Superfamily of plant, fungal and bacterial peroxidases. Curr. Opin. Struct. Biol. 2:388-393.

Werner, S., Sugui, J. A., Steinberg, G., and Deising, H. B. 2007. A chitin synthase with a myosin-like motor domain is essential for hyphal growth, appressorium differentiation, and pathogenicity of the maize anthracnose fungus Colletotrichum graminicola. Mol. Plant-Microbe Interact. 20:1555-1567.

Yu, J. H., Hamari, Z., Han, K. H., Seo, J. A., Reyes-Dominguez, Y., and Scazzocchio, C. 2004. Double-joint PCR: A PCR-based molecular tool for gene manipulations in filamentous fungi. Fungal Genet. Biol. 41:973-981.

\section{AUTHOR-RECOMMENDED INTERNET RESOURCE}

Broad Institute BLAST Similarity Search database: www.broadinstitute.org/annotation/genome/colletotrichum_group/ Blast.html 